Chapter 5

\title{
Treatment of Myelodysplastic Syndrome and Acute Myeloid Leukemia by Immunomodulatory and Epigenetic Drugs
}

\author{
Ota Fuchs
}

Additional information is available at the end of the chapter

http://dx.doi.org/10.5772/52099

\section{Introduction}

Acute myeloid leukemia (AML) is associated with poor prognosis in elderly patients. More effective, less toxic therapies for older patients with AML who are not eligible for standard intensive induction therapy or have refractory or relapsed disease after chemotherapy are urgently needed. Epigenetic approaches with hypomethylating agents and histone deacetylase inhibitors and immunomodulatory drugs used in advance in the treatment of patients with myelodysplastic syndrome (MDS) have been also studied in patients with AML [1-15].

MDS is a diverse goup of clonal hematopoietic stem cell disorders manifested by ineffective production of blood cells with varying need for transfusions, risk of infection, and risk of transformation to AML. Epigenetic changes, such as DNA methylation, histone acetylation, and RNA interference alter gene expression impacting disease biology and play an important role in the pathogenesis of both, MDS and AML. Hypermethylation of CpG islands in the promoters of key genes involved in cell cycle regulation, apoptosis, tumor suppressor control and in response to chemotherapy and the consequent silencing of their expression is well documented in MDS. Hypermethylated DNA sequences of key cellular machinery provide an attractive potential therapeutic target for the treatment of MDS. DNA methylation and histone modification not only regulate the expression of protein-encoding genes but also microRNAs (miRs), such as let-7a, miR-9, miR-34a, miR-124, miR-137, miR-148, miR-203 and miR-223 [16-22]. The only approved way to inhibit DNA methylation is to use clinically available inhibitors of enzymes- DNA methyltransferases (DNMTs). Treatment with DNMT inhibitors is a rational strategy with the aim to reinduce the expression of epigenetically silenced genes for tumor suppressors and other targeted genes, often connected with response 
to chemotherapy. It can induce a broad spektrum of apoptotic pathways. This strategy is valid not only for MDS but for human cancer generally, including AML. 5-Aza-cytidine (azacidine, Vidaza) and 5-aza-2'-deoxycytidine (5-azaCdR decitabine) have become the standard in the treatment of patients with higher-risk MDS, in particular older individuals, where intensive chemotherapy and allogeneic stem cell transplantation is not possible.

Azacitidine (Vidaza, Celgene Corporation, Summit, NJ, USA or Celgene Europe Ltd., Winsdor, UK) was the first drug approved for the treatment of MDS in the United States and in the European Union. Decitabine (Dacogen, Eisai Inc., Woodcliff Lake, NJ, USA under license from Astex Pharmaceuticals, Inc., Dublin, CA, USA) received initial regulatory approval from the US Food and Drug Administration (FDA) in May 2006 for the treatment of patients with all MDS subtypes [23-25]. Since then, decitabine has also gained regulatory approval in Russia, Malaysia, South Korea, the Philippines, Uruguay, Chile, Argentina, Peru, Colombia, and Brazil, and is considered for approval in other countries. European Organisation for Research and Treatment of Cancer (EORTC) conducted study, which failed to reveal a significant improvement in overall survival, time to AML transformation and death, for low-dose decitabine compared to the best supportive care [26-31].

About $80-90 \%$ of 5 -aza-cytidine is incorporated into RNA which disrupts nucleic acid and protein metabolism leading to apoptosis. The rest of 5-azacytidine (10-20\%) inhibits DNA synthesis through conversion to decitabine triphosphate and subsequent DNA incorporation. Recently, precise mechanism of azacitidine action has been described. Azacitidine inhibits ribonucleotide reductase subunit and causes perturbation of the pool of deoxyribonucleotide triphosphates.

The median survival for azacitidine-treated patients with AML $\left(75 \mathrm{mg} / \mathrm{m}^{2} /\right.$ day for 7 days) in a phase III randomized trial was 24.5 months, compared with 16 months for AML patients receiving conventional care regimens [4]. Complete remisson rates were $18 \%$ for patients receiving azacitidine, $15 \%$ for patients receiving low-dose cytarabine, and $55 \%$ for patients receiving intensive induction therapy [4,5]. Multicenter, phase II study of decitabine (20 $\mathrm{mg} / \mathrm{m}^{2} /$ day for 5 days) for the first-line treatment of older patients with AML found remissions in $25 \%$ of patients, with a median overall survival of 7.7 months and a 30 -day mortality rate of $7 \%$ [5]. Another study in older AML patients treated with a 10-day schedule of decitabine showed that $47 \%$ of patients achieved complete remission without added toxicity [32]. Despite these encouraging results, in a randomized phase III trial, decitabine produced complete remission in $18 \%$ older patients with AML but without the significant improvement in overall survival in comparison with patients receiving supportive care or low-dose cytarabine [25]. Several new studies show a little better results [33, 34]. New randomized studies evaluating single-agent decitabine versus conventional treatment are warranted. A low incidence of treatment-related toxicity has been reported for both these agents, azacitidine and decitabine, supports their use for older AML patients, mainly for those unable or unwilling to receive standard intensive chemotherapy.

Decitabine maintains normal hematopoietic stem cell (HSC) self-renewal but induces terminal differentiation in AML cells. AML cells express low levels of the key late differentiation factor CEBPE (CCAAT/enhancer binding protein epsilon). CEBPE promoter CpGs are usually hypo- 
methylated during granulocyte maturation but are significantly hypermethylated in AML cells [35]. Decitabine-induced hypomethylation is greatest at these and other promoter CpGs that are usually hypomethylated with myeloid maturation, accompanied by cellular differentiation of AML cells. In contrast, decitabine-treated normal HSC retained immature morphology. High expression of lineage-specifying factor and aberrant epigenetic repression of some late differentiation factors distinguishes AML cells from normal HSCs and could explain the contrasting differentiation and methylation responses to decitabine. Decitabine induced upregulation of several apoptosis-related genes, in particular of DAP-kinase 1 and BCL2L10. $B C L 2 L 10$ was hypermethylated in $45 \%$ of AML but not in healthy controls [36].

Another inhibitors of DNMTs (5,6-dihydro-5-azacytidine, 2'-deoxy-5,6-dihydro-5-azacytidine, a second-generation hypo-methylating agent SGI-110/a dinucleotide of decitabine and deoxyguanosine linked with a natural phosphodiester linkage/, zebularine, procaine, epigallocatechin-3-gallate, and N-phthalyl-L-tryptophan) are in preclinical studies or in clinical trials $[37,38]$.

The second epigenetic target for which drugs are available is histone deacetylation. There are several histone deacetylases (HDAC) inhibitors (romidepsin, vorinostat, belinostat, sodium phenylbutyrate, valproic acid, entinostat, and mocetinostat) in preclinical studies or in clinical trials $[6,10,11]$. Vorinostat and valproic acid received approval from the US FDA and are available for clinical use in the USA.

Clinical studies with dual pharmacologic targeting of DNMT and HDAC enzymes (azacitidine and phenylbutyrate or decitabine plus vorinostat) reported overall response rate of $22 \%$ in MDS/AML patients and supported preclinical results where synergistic anticancer activity was found $[12,39,40]$.

Clinical benefit from the immunomodulatory agent lenalidomide (CC5013, Revlimid $\left.{ }^{\circledR}\right)$ in patients with lower-risk MDS associated with deletion of the long arm of chromosome 5 (del(5q)) led to its 2005 FDA approval for red blood cell transfusion-dependent anemia due to low or intermediate-1 risk MDS associated with a chromosome $5 q$ deletion with or without additional cytogenetic abnormalities. Lenalidomide functions through immunomodulatory, anti-inflammatory, anti-angiogenic and direct neoplastic cells inhibitory mechanisms [41-43]. The highly encouraging results with lenalidomide in del(5q) lower-risk MDS were not repeated in $\operatorname{del}(5 q)$ AML. The cause of this difference is in many cases deletion of another commonly deleted region $5 \mathrm{q} 31$ and not of the 5q32-33 including RPS14. However, there is the clear activity of lenalidomide in a subset of patients with AML [8, 9]. Safety, efficacy and biological predictors of response to sequential azacitidine and lenalidomide for elderly patients with acute myeloid leukemia were also studied [14]. This therapy was well tolerated with encouraging clinical and biological activity.

The regulation of gene expression by DNA methylation

DNA methylation is a covalent modification at position $\mathrm{C} 5$ of the cytidine ring in the context of a CPG dinucleotide. This methylation is catalysed by a family of DNMTs including DNMT1, DNMT3A and DNMT3B. DNMT1 is required for maintenance methylation during DNA replication. DNMT3A and DNMT3B function in de novo methylation [44-47]. CpG rich 
regions called $\mathrm{CpG}$ islands are present in about half of human gene promoters. Methylation of these $\mathrm{CpG}$ islands is associated with transcriptional silencing from the involved promoters. When the CpG islands are highly methylated, they bind specific proteins which recruit transcriptional co-repressors such as histone deacetylases (HDACs). Epigenetic silencing is also associated with histone $\mathrm{H} 3$ lysine 9 (H3K9) methylation. This modification is associated with closed chromatin and results also in transcriptional suppression. Alterations in DNA methylation are important in the pathogenesis of MDS [48]. Increasing evidence shows aberrant hypermethylation of genes occurring in and potentially contributing to pathogenesis of MDS. The tumor suppressor and cell cycle regulatory gene CDKN2B (cyclin-dependent kinase inhibitor 2B) is an example of hypermethylated gene in MDS resulting in silenced expression of this cell cycle inhibitor p15 ${ }^{\mathrm{INK} 4 \mathrm{~B}}$ (cyclin-dependent kinase 4 inhibitor B) and in uncontrolled cell cycle progression and cellular proliferation. CDKN2B methylation is frequent in refractory anemia with excess blasts in transformation, therapy-related MDS, and in chronic myelomonocytic leukemia [49-52]. Increased methylation of CDKN2B gene is connected with disease progression. Methylation level of $C D K N 2 B$ gene might be used as a marker of leukemic transformation in MDS [53].

Reversal of aberrant methylation by the treatment with hypomethylating agents leads to reexpression of silenced tumor suppressor genes and some other genes, often connected with response to chemotherapy (CDKN2B, cyclin-dependent kinase inhibitor 2A /CDKN2A/ coding for p16 ${ }^{\mathrm{INK} 4 \mathrm{~A}}$, the cell-adhesion genes /cadherin-1/CDH-1/, cadherin-13/CDH-13/, and immunoglobulin superfamily member 4 /IGSF4/, the pro-apoptotic death-associated protein serine/threonine kinase gene /DAP-kinase/, the suppressor of cytokine signaling-1/SOCS1/, the reversion-induced LIM homeodomain containing gene /RIL/, a ligand-dependent suppressor deleted in colorectal cancer $/ D C C /$, a growth regulatory and tumor suppressor gene hypermethylated in cancer /HIC1/, dinucleosidetriphosphatase-fragile histidine triad gene / FHIT/ involved in purine metabolism, calcitonin, arachidonate 12- lipoxygenase /ALOX12/ involved in the production and metabolism of fatty acid hydroperoxidases, glutathione Stransferase Mu1/GSTM1/, testes-specific serine protease 50 /TSP50/, O-6-methylguanineDNA methyltransferase /MGMT/, Krüppel like factor $11 / K L F 11 /$, oligodendrocyte lineage transcription factor $2 / O L I G 2 /$, estrogen receptor alpha /ESR1/, progesterone receptors PGRA and PGRB, RAS association domain family1A /RASSF1/, functioning in the control of microtubule polymerization and potentially in the maintenance of genomic stability, and $B L U$, both tumor suppressors genes located at 3p21.3, retinoic acid receptor beta $/ R A R B /$, a nuclear transcription factor which mediates cellular signaling, cell growth and differentiation, and neutrophic tyrosine kinase receptor, type 1 /NTRK1/), which is needed to transmit signals for cell growth and survival [54-57].

In the recent years, the discovery of a series of mutations in patients with MDS has provided insight into the pathogenesis of MDS. Among these alternations have been mutations in genes, such as IDH1, IDH2, TET2, and DNMT3A, which affect DNA methylation [58-61]. These mutations are discussed in the special chapter. 


\section{Types of histone methylation modification and their regulatory mechanisms}

Histone methylation is carried out by several histone methyltransferases that methylate lysine (HKMTs) or arginines (PRMTs) in histone tails [62-65]. The four core histones, H2A, $\mathrm{H} 2 \mathrm{~B}, \mathrm{H} 3$, and $\mathrm{H} 4$, make up the nucleosome, the main structural unit of chromatin. Some specific histone tail modification, such as methylation of histone 3 lysine tail residue 4 (H3K4), are associated with activation of gene expression, while others, such as methylation of histone 3 lysine 27 (H3K27), are associated with gene repression [66]. These marks are normally carefully controlled by the interplay of sequence-specific DNA binding transcription factors and transcriptional cofactors, many of which are histone-modifying enzymes. The end amino group of lysine can be mono-, di- or tri-methylated. Dependent on this methylation state, the binding affinity of chromatin-associated proteins varies greatly. Methylation of histone 3 lysines 4 and 27 is catalyzed by trithorax and polycomb family of proteins. $\mathrm{H} 3 \mathrm{~K} 27$ is di- and trimethylated by enhancer of zeste homolog 2 (EZH2), a polycomb family protein [67]. The enzyme that reverses H3K27 methylation was not known until the discovery of two demethylases, ubiquitously transcribed tetratricopeptide repeat, $\mathrm{X}$ chromosome (UTX) and Jumonji domain containing 3 (JMJD3), both of which are members of the Jmje domain-containing protein family [68]. EZH2 has been reported to be mutated and inactivated in MDS [69], but is also overexpressed in other subsets of MDS [70]. UTX mutations and/or deletions have also been observed in patients with MDS and chronic myelomonocytic leukemia [61, 71-73].

\section{Histone acetylation status}

Acetylation of nucleosomal histones in part regulates gene transcription in most cells. Differential acetylation of nucleosomal histones results in either transcriptional activation (hyperacetylation and an open chromatin configuration) or repression (hypoacetylation and compacted chromatin) [74, 75]. The role of chromatin remodeling in carcinogenesis was studied with the help of inhibitors of HDACs (HDIs). HDIs induce the hyperacetylation of nucleosomal histones in cells resulting in the expression of aberrantly repressed genes (e.g., tumor suppressor genes) that produce growth arrest, terminal differentiation, and/or apoptosis in carcinoma cells, depending on the HDI and dose used, and the cell type [76-79]. The inappropriate recruitment of HDACs provides at least one mechanism by which oncogenes could alter gene expression in favor of excessive proliferation. Thus, orally active HDIs with low toxicity towards normal cells and tissues, which would effectively inhibit tumor growth are needed for epigenetic anticancer therapy. In October 2006, the US Food and Drug Administration (FDA) approved the first drug of this new class, vorinostat (SAHA, Zolinza) for treatment of cutaneous T-cell lymphoma. Several further HDIs (romidepsin, belinostat, sodium phenylbutyrate, valproic acid, entinostat, and mocetinostat) are in clinical trials. HDIs have shown significant activity against a variety of hematological and solid tumors at doses that are well tolerated by patients, both in monotherapy as well as in combination therapy 
with other drugs. Combined DNA methyltransferase and histone deacetylase inhibition are used in experiments in vitro but also in clinical trials in MDS and AML patients [6, 39].

\section{MicroRNAs and epigenetic machinery}

MicroRNAs (miRs) belong to a class of small non-coding regulatory RNA that act through binding to the 3' -UTR of target mRNA and leading to translational repression or degradation of target mRNA at post-transcriptional level. MiRs can directly target epigenetic effectors such as DNMTs, HDACs and polycomb repressive complexes. On the other hand, some miRs (miR-9, 34b/c, 124, 127, 137, 145, 146a, 148, -203, let-7a-3, and others) are epigenetically regulated [80,81].

MiR-29b targets DNMT3A mRNA [18, 82, 83]. In addition, some isoforms of DNMT3B are targeted by miR-148 [84]. MiR-26a, 101, 205 and -214 regulates EZH2 [85-90].

Dostalova Merkerova et al. found nine upregulated genes for miRs located at chromosome $14 q 32$ in CD34+ cells separated from mononuclear cells of bone marrow obtained from MDS patients [91]. 14q32 region contains $40 \mathrm{miR}$ genes with imprinted expression controlled by a distant differentially methylated region. For example miR-127, a member of the $14 \mathrm{q} 32$ region, is involved in B-cell differentiation process through posttranscriptional regulation of BLIMP1, XBP1, and BCL6 genes [91]. BLIMP1 (B lymphocyte induced maturation protein 1) is a zinc finger transcriptional repressor which functions as a master regulátor of terminal differentiation of B cells into plasma cells. XBP1 (X-box binding protein 1) is transcription factor that regulates MHC class II genes by binding to a promoter element referred to as an $\mathrm{X}$ box. BCL6 (B-cell lymphoma 6 protein) is a transcriptional represor which regulates germinal center $\mathrm{B}$ cell differentiation and inflammation.

\section{Protein EVI1 and epigenetic machinery}

EVI1 (the ecotropic viral integration site 1) is encoded by gene on chromosome 3q26 [92-95]. The oncoprotein EVI1 and the DNMT3 co-operate in bindig and de novo methylation of target DNA [96]. EVI1 forms a bridge between the epigenetic machinery and signaling pathway [97, 98]. EVI1 represses PTEN (phosphatase and tensin homolog) expression and activates PI3K/AKT (Protein kinase B)/mTOR via interaction with polycomb proteins [97, 98]. Overexpression of EVI1 predicts poor survival in MDS and AML [99]. MDS patients with inversion of chromosome 3 and with EVI1 transcriptional activation achieved morphological and cytogenetic response to azacitidine [100].

\section{Epigenetic therapy in MDS and AML}

Treatment with DNMT inhibitors is a rational strategy with the aim to reinduce the expression of epigenetically silenced genes for tumor suppressors and other targeted genes, often 
connected with response to chemotherapy. Responses to therapy with DNMT inhibitors are up to now not fully elucidated. We have no clear evidence for DNMT overexpression in MDS and the decrease in global methylation after treatment with demethylating agents has not correlated with disease response. Changes in differentiation and/or apoptosis, and induction of a immune response can be also involved [28-38, 101].

DNA methylation of upstream regulatory element (URE) plays an important role in downregulation of transcription of PU.1 gene. PU.1 is the transcription factor and tumor suppressor necessary for myeloid differentiation. Azacitidine treatment demethylated in vitro URE leading to upregulation of PU.1 followed by derepression of its transcriptonal targets and onset of myeloid differentiation [102]. DNA demethylation and a shift from a repressive histone profile to a more active profile that includes the reassociation of RNA polymerase II (Pol II) with the targeted promoters are necessary for tumor suppressor gene reactivation [103].

Even if a complete understanding of the mechanism of action of azanucleotides remains to be elucidated, their pharmacodynamic effects promote enhanced survival independently of any ability to eliminate the MDS clone. The MDS clone persists in many patients treated by DNMT inhibitors but this clone is modulated and hematologic function is improved together with survival of patients.

It has been almost 50 years since the synthesis and antitumor activity of azacitidine (AC) was described [104, 105]. AC is a pyrimidine nucleoside analog of cytidine and is characterized by a presence of an extra nitrogen atom at position $\mathrm{C} 5$ of pyrimidine ring. This modification leads to a blockade of cytosine methylation via a covalent trapping of DNMT. AC is believed to utilize a dual mechanism of action following its phosphorylation: 1) hypomethylation of DNA at low doses and 2) cytotoxicity due to the incorporation into RNA and apparent interaction with protein biosynthesis at high doses. To overcome cytotoxicity, a deoxy analog of AC, 5-aza-2'-deoxycytidine (decitabine, DAC) was synthesized, which is incorporated only into the DNA following its phosphorylation. DAC significantly inhibits DNA methylation at lower concentrations and with less cytotoxicity in comparison with AC [106]. Both, AC and DAC, possess high cytotoxicity at their maximal tolerated doses and are unstable in aqueous solution.

\section{Azacitidine clinical studies}

Patients with MDS were randomly treated with either azacitidine or best supportive care in the CALGB 9221 study [107]. A total of 191 patients with a median age of 68 years were used. Azacitidine $\left(75 \mathrm{mg} / \mathrm{m}^{2} /\right.$ day $)$ was injected subcutaneously in 7-day cycles beginning on days $1,29,57$, and 85 (every 28 days). If a beneficial effect was not demonstrated by day 57 and no significant toxicity other than nausea or vomiting had occured, the dose of AC was increased by $33 \%$. Once benefit occured on a particular dosage, AC was continued unless toxicity developed. Patients were assessed after the fourth cycle. Those who achieved complete response (CR) continued on AC until either CR or relapse occured. After 4 months of 
supportive care, any patients with worsening dinase were permitted to cross over to treatment with AC. Overall, 59\% of patients had either refractory anemia with excess blasts (RAEB) or RAEB in transformation (RAEB-T) according to French-American-British (FAB)defined criteria, and $65 \%$ of patients were red blood cell transfusion dependent. Sixty percent of patients in the azacitidine arm (including $7 \%$ of patients with CR, 16\% with a partial response $/ \mathrm{PR} /$, and $37 \%$ with hematologic improvement $/ \mathrm{HI} /$ ), compared with $5 \%$ of patients in the control arm, responded to treatment (p๑0.001). The median time to leukemic transformation or death was 21 months in patients treated with AC compared with 12 months in the best supportive care $(\mathrm{p}=0.007)$. The median overall survival was 20 months for AC-treated patients compared with 14 months for patients assigned to best supportive care. $53 \%$ of patients on best supportive care received azacitidine after crossover. A further benefit of AC over supportive care was a significant improvement in quality of life (physical functioning, fatigue, dyspnea) in patients treated with AC compared with patients in the control arm. AC did not increase the rate of infection or gastrointestinal bleeding above the rate associated with underlying disease.

The AZA-001 trial was an international, randomized phase III study designed to test the hypothesis that AC significantly extends overall survival in patients with MDS compared with standard care regimens including best supportive care, low-dose cytarabine (ara-C, 20 $\mathrm{mg} / \mathrm{m}^{2}$ for 14 days every 28 days for at least 4 cycles), or intensive chemotherapy consisting of induction with higher dose of ara-C (100-200 mg/m²/day for 7 days plus 3 days of daunorubicin $45-60 \mathrm{mg} / \mathrm{m}^{2} /$ day, idarubicin $9-12 \mathrm{mg} / \mathrm{m}^{2} /$ day, or mitoxantrone $8-12 \mathrm{mg} / \mathrm{m}^{2} /$ day ) [108]. A total of 358 patients with higher-risk MDS were randomly assigned to either azacitidine as in CALGB 9221 or to standard of care. Median age of patients was 69 years. After a median follow-up of 21.1 months, the median survival time was significantly better in azacitidine patients compared with standard of care options (24.5 versus 15.0 months, respectively $\mathrm{p}=0.001$ ) irrespective of age, percentage of marrow blasts or karyotype. In particular, overall survival was prolonged for azacitidine in patients with $-7 / \operatorname{del}(7 \mathrm{q})$ cytogenetic abnormality, median overall survival was 13.1 months in the azacitidine group compared with 4.6 months in the standard of care group ( $\mathrm{p}=0.00017$ ). Progression to AML was significantly delayed in patients treated with AC (17.8 months in the AC group versus 11.5 months in the standard of care group p॰0.001). Transfusion requirements and rate of infections were also significantly improved in azacitidine patients.

Continued azacitidine therapy beyond time of first response improves quality of response in patients with higher-risk myelodysplastic syndromes in $48 \%$ of patients [109]. This secondary analysis of the AZA-001 phase III study evaluated the time to first response and the potential benefit of continued AC treatment beyond first response in responders. Overal, 91 of 179 patients achieved a response to azacitidine; responding patients received a median of 14 treatment cycles (range, 2-30). Median time to first response was 2 cycles (range, 1-16). Although $91 \%$ of first responses occured by 6 cycles, continued azacitidine improved response in $48 \%$ of patients. Best response was achieved by $92 \%$ of responders by 12 cycles. Median time from first response to best response was 3.5 cycles ( $95 \%$ confidence interval 
(CI), 3.0-6.0) in 30 patients who ultimately achieved a complete response, and 3.0 cycles (95\% CI, 1.0-3.0) in 21 patients who achieved a partial response.

French group studied a retrospective cohort of 282 higher-risk MDS treated with azacitidine, including 32 patients who concomitantly received erythropoiesis stimulating agents (ESA) for a median of 5.8 months after azacitidine onset [110]. Hematologic improvement was reached in $44 \%$ of the ESA and $29 \%$ of the no-ESA patients. Transfusion independence was achieved in $48 \%$ of the ESA and $20 \%$ of the no-ESA groups. Median overall survival was 19.6 months in the ESA and 11.9 months in the no-ESA patients.

Platelet doubling after the first azacitidine cycle is a promising independent predictor for response and overall survival in MDS, chronic myelomonocytic leukemia (CMML) and AML patients in the Dutch azacitidine patients [111].

\section{Decitabine clinical studies}

Two studies used 3-day, 9-dose regimens requiring inpatient hospitalization and two studies used 5-10 day decitabine regimens intended for outpatient administration [23, 25].

The US D-0007 phase III study compared decitabine $\left(15 \mathrm{mg} / \mathrm{m}^{2}\right.$ continuous 3-hour intravenous infusion every 8 hours for 3 days) with supportive care in 170 patients with a confirmed diagnosisof de novo or secondary MDS. The median age of enrolled patients was 70 years (range, 30-85 years). Most patients (69\%) had intermediate (Int)-2- or high- risk diseaseas defined by the International Prognostic Scoring System criteria, and were red blood cell transfusion dependent (71\%) [23]. No significant difference was seen in median overall survival (OS) between patients treated with decitabine and those receiving supportive care (14.0 versus 14.9 months, respectively; $\mathrm{p}=0.636$ ). The median duration of response to decitabine treatment was 10.3 months (range, 4.1-13.9 months). Patients received a median of 3 courses of decitabine treatment (range, 0-9).

EORTC 06011 phase III study compared decitabine given on a 3-day inpatient regimen (15 $\mathrm{mg} / \mathrm{m}^{2}$ intravenously over 4 hours three times a day for 3 days, every 6 weeks, for a maximum of 8 cycles) with supportive care. A total of 233 patients with primary or secondary MDS, or CMML defined by FAB classification (median age, 70 years; range, 60 to 90 years) were enrolled [25]. 53\% had poor-risk cytogenetics, and the median MDS duration at random assignment was 3 months. The median OS prolongation with decitabine versus best supportive care was not statistically significant (median OS, 10.1 versus 8.5 months; $\mathrm{p}=0.38$ ).

M.D. Anderson Cancer Center ID03-0180 randomized phase II study compared three outpatient decitabine schedules. In this single-institution study, 95 patients (77 with MDS, and 18 with CMML) were randomized to receive $20 \mathrm{mg} / \mathrm{m}^{2} /$ day intravenously for 5 days, 20 $\mathrm{mg} / \mathrm{m}^{2} /$ day subcutaneously for 5 days, or $10 \mathrm{mg} / \mathrm{m}^{2} /$ day intravenously for 10 days. Thus, all patients received the same $100 \mathrm{mg} / \mathrm{m}^{2}$ total decitabine dose in each treatment cycle. Overall, 32 patients (34\%) achieved CR and 69 patients (73\%) had an objective response. The 5-day intravenous schedule, which had the highest dose-intensity, was selected as optimal. The 
CR rate in that arm was $39 \%$ compared with $21 \%$ in the 5 -day subcutaneous arm and $24 \%$ in the 10-day intravenous arm $(\mathrm{P}<0.05)$. The high dose-intensity arm (the 5-day intravenous schedule) was also superior at inducing hypomethylation at day 5 and at activating the expression of the cell cycle inhibitor $\mathrm{p} 15^{\mathrm{INK} 4 \mathrm{~B}}$ at days 12 or 28 after therapy. The 5-day intravenous schedule of decitabine optimizes epigenetic modulation and clinical responses in MDS.

North American multicenter DACO-020 ADOPT phase II study started on the results of the study of M.D. Anderson Cancer Center dealing with efficacy and safety of decitabine in the 5-day intravenous schedule, every 4 weeks in 99 patients with MDS (de novo or secondary). The primary end point was the overall response rate (ORR) by International Working Group criteria. Secondary end points included cytogenetic responses, hematological improvement, response duration, survival and safety. The ORR was 32\% (17 complete responses plus 15 marrow complete responses and the overall improvement rate was $51 \%$, which included $18 \%$ of hematologic improvement. Decitabine can be administered in an outpatient petting with comparable efficiacy and safety to the US FDA- approved impatient regimen.

\section{Comparison of azacitidine and decitabine}

Azacitidine and decitabine appear to have similar administration costs. As far as adverse events azacitidine is well tolerated. Grade 3 and 4 neutropenia was observed for $91 \%$ patients in the azacitidine treated group, and $76 \%$ in the best conventional care group. Grade 3 and 4 thrombocytopenia occurred among $85 \%$ of patients in the azacitidine treated group and $80 \%$ in the best conventional care group. Higher risk of febrile neutropenia (23\%) was described in the US D-0007 phase III decitabine study. In this study $87 \%$ of neutropenia and $85 \%$ of thrombocytopenia in response to decitabine were reported. In AZA-001 study the median OS was 24.5 months for azacitidine compared with 15.0 month for the best conventional care [108]. Decitabine has not demonstrated a survival advantage compared with the best conventional care (14.0 versus 14.9 months) [23]. In the EORTC 06011 study, the median OS was 10.1 months for decitabine and 8.5 months for supportive care [25]. Comparing results from different studies suggests similar median number of cycles to first response for azicitidine ( 2.3 cycles /64 days/ in CALGB 9221 study) and decitabine ( 2 cycles /3.3 months/ in the D-0007 study and 2 cycles $/ 2$ months/ in DACO-020 ADOPT trial) [23, 106]. For azacitidine treated patients, the median duration of response was 15 months in CALGB 9221 study [107] and 13.6 months in AZA-001 trial [108]. For decitabine treated patients, the median duration of response ranged from 8.6 months for EORTC 06011 study [25], 10 months in the DACO-020 ADOPT trial, to 10.3 months in the D-0007 study [23].

\section{Biomarkers of sensitivity to hypomethylating agents}

A number of research groups have focused on the identification of methylation patterns that would predict for response in MDS. No such profile exists. Baseline methylation pat- 
terns were not associated with response to hypomethylating agents. The significant correlation was observed between reduced methylation over time and clinical outcome. Further studies of methylation dynamics both before and after treatment with hypomethylating agents will be useful to determine the ability of these markers to direct treatment. DNA methylation of upstream regulatory element (URE) controlling the transcription of PU.1 gene may be a new biomarker for the prediction which patiens will bendit from therapy by hypomethylating agents [102].

Several other biomarkers, such as mutations in TET2 gene and levels of miR-29b have been reported to be associated with responses to azacitidine and decitabine, respectively. TET2 is a protein involved in the conversion of 5-methylcytosine to 5-hydroxymethylcytosine and could therefore result in passive induction of DNA methylation. TET2 mutations were recently reported to be associated with clinical response to azacitidine but not with survival. Contradictory results were obtained by another research group [112]. TET2 mutations were described in $15 \%$ of 86 patients. The response rate to $\mathrm{AC}$ was $82 \%$ in the mutated patients and $45 \%$ in the nonmutated patients with wild TET2 gene. Mutated TET2 $(p=0.04)$ and favorable cytogenetic risk (intermediate risk: $\mathrm{p}=0.04$, poor risk: $\mathrm{p}=0.048$ compared with good risk) independently predicted a higher response rate. TET2 status may be a genetic predictor of response to AC, independently of karyotype. Expression levels of DNMT1, an enzyme involved in maintenance of methylation patterns, are regulated by miR-29b. Higher levels of $\mathrm{miR}-29 \mathrm{~b}$ were associated with clinical response to decitabine.

Circulating cell-free DNAs from plasma and serum of patients with MDS can be used to detect genetic and epigenetic abnormalities. The plasma DNA concentration was found to be relatively high in patients with higher blast cell counts in bone marrow.

\section{Resistance to hypomethylating agents}

There is a subgroup of patients with MDS who do not respond to therapy with hypomethylating agents and a large, growing cohort of patients that lose progress while on azacidine or decitabine therapy. Since the mechanism of resistance to hypomethylating agents are not known, selection of therapy is largely empiric but must take into account the age, comorbidities, and performance status of the patient, as well as the characteristics of the disease at the time of treatment failure. Higher intensity approaches and allogeneic stem cell transplantation can yield improved response rates and long-term disease control but should be limited to a selected cohort of patients who can tolerate the treatment-related morbidities. For the majority of patients who likely will be better candidates for lower intensity therapy, several novel, investigational approaches are becoming available. Among these are newer nucleoside analogues, inhibitors of protein tyrosine kinases, molecules that interact with redox signaling within the cell, immunotherapy approaches, and others.

In clinical trials, some patients do not respond to hypomethylating agents initially (primary resistance) and most patients who initially respond to treatment, eventually relapse (secondary resistance) despite continued therapy with hypomethylating agents. Most primary mecha- 
nisms of resistance are based on metabolic pathways. The primary resistance is caused by the insufficient intracellular concentration of nucleoside triphosphates resulting from deoxycytidine kinase deficiency (DCK mutations or aberrant gene expression), increased deamination by cytidine deaminase (CDA), or high dNTP pools. Higher ratio of CDA/DCK in a subset of patients means that decitabine is less activated through mono-phosphorylation by DCK and more inactivated through deamination by CDA in non-responders. Secondary resistance is likely due alternate progression pathways as a less aberrant DNA methylation was found during the treatment with hypomethylating agent than at diagnosis, and there were no significant changes in decitabine metabolism gene expression.

\section{New hypomethylating agents}

Current hypomethylating agents are limited due to route of administration and potency as inducers of DNA hypomethylation. An oral compound or an agent with a better pharmacodynamic profile could improve hypomethylating therapy of MDS patients. Initial results with an oral formulation of 5-azacytidine have been reported.

$2^{\prime}, 3^{\prime}, 5^{\prime}$-triacetyl-5-azacytidine demonstrates significant pharmacokinetic improvements in bioavailability, solubility, and stability over the parent compound 5-azacytidine. In vivo analyses indicated a lack of general toxicity coupled with significantly improved survival. Pharmacodynamic analyses confirmed its ability to suppress global methylation in vivo. Esterified nucleoside derivatives may be effective prodrugs for azacitidine and encourages further investigation and possible clinical evaluation.

A new salt derivative, oral decitabine mesylate, is used in ongoing trials. A barrier to efficacious and accessible DNMT1-targeted therapy is cytidine deaminase, an enzyme highly expressed in the intestine and liver that rapidly metabolizes decitabine int into inactive uridine counterparts, severely limiting exposure time and oral bioavailability. Oral administration of 3,4,5,6-tetrahydrouridine (THU), a competitive inhibitor of cytidine deaminase, before oral decitabine extended decitabine absorption time in mice and nonhuman primates and widened the concentration-time profile. Therefore, the exposure time for S-phase-specific depletion of DNMT1 is increased without the high peak of decitabine levels that can cause DNA damage and cytotoxicity. On the other hand, decreased DNA methylation in intermediate and high risk AML patients with DNMT3A mutation was linked with higher relapse rates and an inferior overall survival [113].

5,6-dihydro-5-azacytidine (DHAC) and 2'-deoxy-5,6-dihydro-5-azacytidine (DHDAC) are hydrolytically stable. There is no evidence of significant genotoxicity and/or mitochondrial toxicity on mammalian cells. Both compounds are a less toxic alternative of azacitidine and decitabine and may also be of therapeutic interest.

Another compounds actively being studied in clinical trials are SGI-110 and CP-4200, a second generation hypomethylating agents [38]. One of the limitations of the nucleoside analogues in the clinical trials has been the side effects, such as thrombocytopenia and neutropenia, which are probably caused by cytotoxic effects associated with the drug's in- 
corporation into the DNA or RNA independently of their DNA hypomethylation value. This has encouraged the search for inhibitors of DNA methylation that are not incorporated into DNA or RNA.

Zebularine is a cytidine deaminase inhibitor that also displays antitumor and DNA demethylating properties. Zebularine is a cytidine analog that contains a 2-( $1 H)$-pyrimidinone ring.

The drug procainamide, approved by the FDA for the treatment of cardiac arrythmias, and procaine, a drug approved by the FDA for use as a local anesthetic, were proposed as nonnucleoside inhibitors of DNA methylation. This action is thought to be mediated by their binding to GC-rich DNA sequences. Both, procaine and procainamide, are derivatives of 4amino-benzoic acid.

Dietary phytochemicals, tea catechins, polyphenols, particularly (-)-epigallocatechin-3-gallate decreased the levels of 5-methylcytosine, DNMTs activity, mRNA and protein levels of DNMT1, DNMT3A and DNMT3B and also decreased histone deacetylase aktivity and stimulated re-expression of the mRNA and proteins of silenced tumor suppressor genes.

N-phthalyl-L-tryptophan (RG108) and its dicyclo-hexyl-amine salt effectively blocked DNA methyltransferases in vitro and did not cause covalent enzyme tramping in human cell line. Incubation of cells with RG108 resulted in signifiant demethylation of genomic DNA without any detectable toxicity. RG108 caused demethylation and reactivation of tumor suppressor genes.

\section{Combinations of hypomethylating agents with histone deacetylase inhibitors or other drugs}

In vitro, most of histone deacetylase inhibitors (HDACI) have been shown to have synergistic activity when combined with either azacitidine or decitabine. Therefore, phase I and II clinical trials were performed. Combination of decitabine and valproic acid was safe and active and time to response was accelerated [6,12]. A randomized phase II trial has been conducted at M.D. Anderson Cancer Center comparing decitabine versus decitabine in combination with valproic acid $[6,12,39]$. Results did not show any significant benefit with the combination of decitabine and valproic acid. Similar results were obtained with combination of azacitidine and MS-275 (Entinostat), a potent HDACI [12, 39].

Phase I trial for combination of lenalidomide with azacitidine has shown this combination to be very safe and clinically active in MDS [114]. In this study 18 patients ( 2 intermediate 1-, 10 intermediate 2- and 6 high- risk) were enrolled with median age 68 years (range, 52 to 78 years). Interval from diagnosis was 5 weeks (range, 2 to 106 weeks) and follow-up was 7 months (range, 1 to 26 months). Azacitidine ( $75 \mathrm{mg} / \mathrm{m}^{2} /$ day) on days 1 through 5 and lenalidomide $(10 \mathrm{mg})$ on days 1 through 21 were used. The combination of lenalidomide and azacitidine is well tolerated with encouraging clinical activity. 


\section{Lenalidomide with potent immunomodulatory, antiangiogenic and direct neoplastic cell inhibitory activity}

Interstitial deletions involving long arm of chromosome 5 are one of the common cytogenetic abnormalities in MDS patients [115-117]. MDS with isolated del(5q) in which the sole cytogenetic abnormality is del(5q) is a distinct entity with a risk of evolution into AML of approximately $10 \%$. It is characterized by macrocytic anemia with or without other cytopenias and/or thrombocytosis. Myeloblasts comprise less than 5\% of bone marrow and less than $1 \%$ of peripheral blood.

Lenalidomide [3-(4-amino-1-oxo1,3-dihydro-2H-isoindol-2-yl)piperidine-2,6-dione] is 4-amino-glutarimide analog of thalidomide with potent immunomodulatory, antiangiogenic and direct neoplastic cell inhibitory activity [118-120]. Thalidomide was synthesized in Germany, in 1954, from $\alpha$-phtaloylisoglutamine, to be used as sedative and antimetic drug. In 1957, after a short period of preclinical studies, thalidomide was approved for first trimester gestational sickness in humans. The appearance of malformations such as phocomelia in the newborn banned its use three years later. The US Food and Drug Administration (FDA) approved thalidomide in 1998 for the treatment of erythema nodosum leprosum. A small but consistent fraction of transfusion-dependent MDS patients achieved transfusion independence by treatment with thalidomide.

Lenalidomide was developed in order to avoid thalidomide side effects (sedation and neuropathy), and to increase efficacy [118-120]. Lenalidomide shares a number of structural and biological properties with thalidomide but is safer and more potent than thalidomide. Lenalidomide was first studied in a single- center trial [121]. Erythroid and cytogenetic responses were achieved in a study of 43 patients with MDS, particularly in patients with isolated del(5q31-33) [28]. Lenalidomide was administered in three different dosing schedules: $25 \mathrm{mg}$ daily, $10 \mathrm{mg}$ daily, and $10 \mathrm{mg}$ daily for 21 days of each 28-day cycle [121]. The erythroid response rates were highest in patients with the International Prognostic scoring system (IPSS) low or intermediate 1 risk MDS. Transfusion independence was achieved in 20 of 32 patients (63\%), and three additional patients had reduced red blood cells transfusion needs [121]. Ten of 12 patients $(83 \%)$ with del(5q31) experienced major erythroid responses, defined as sustained transfusion independence, compared with a $57 \%$ response rate in patients with a normal karyotype and a $12 \%$ response rate in patients with other cytogenetic abnormalities. Complete cytogenetic remissions were achieved in $75 \%$ of the del(5q31) patients ( 9 of 12 of these patients), with one additional patient achieving at least a 50\% decreases in abnormal metaphases [121]. Myelosuppression (neutropenia and/or thrombocytopenia) was the most common adverse event, but it was dose-dependent, favoring the $10 \mathrm{mg}$ daily dose for 21 days of each 28-day cycle. 


\section{Multicenter phase II trials of lenalidomide}

After encouraging results of a single-center trial (MDS-001) [28], the effect of lenalidomide on the 5 q31 deletion MDS syndrome was investigated in a large multicenter phase II study (MDS-003) and led to its FDA approval for red blood cell transfusion-dependent anemia due to low or intermediate-1 risk MDS associated with a chromosome $5 q$ deletion with or without additional cytogenetic abnormalities [122]. The initial schedule was $10 \mathrm{mg}$ of lenalidomide for 21 days every 4 weeks, but the treatment schedule was subsequently amended so that the $10 \mathrm{mg}$ dose was given every day because of the shorter interval between initiation of treatment and a response in the pilot study. Of the 148 transfusion-dependent patients who were included in the study, 46 were treated on the 21-day schedule and 102 received continuous daily dosing. Overall, 112 (76\%) patients responded to treatment with a median time to response 4.6 weeks. Among these, 99 no longer needed transfusions by week 24 , while the remaining 13 patients had a reduction of $50 \%$ or greater in the number of transfusions required. There was no significant difference in response rate between the two treatment schedules. Response rate was independent of additional chromosomal aberrations. Patients with pretreatment thrombocytopenia had an inferior outcome. Almost half of the patients, including some with complex karyotypes, had a complete cytogenetic response. Neutropenia and thrombocytopenia were the most common treatment-associated adverse events. Most other adverse events were of low or moderate severity and included pruritus, rash, diarrhea, and fatigue. Adjustment of the lenalidomide dose due to intolerance was required in 124 patients, including 93 of those receiving continuous daily dosing and 31 of those receiving 21-day dosing. Thirty patients discontinued lenalidomide treatment because of adverse events including thrombocytopenia or neutropenia, rash AML, anemia, facial edema, congestive heart failure, urticaria, diarrhea, weight loss, renal insufficiency, cerebrovascular accident, dementia, dyspnea, pyrexia, and pneumonia.

However, the European Medicine Agency (EMEA) did not approve lenalidomide for this indication, raising the concern, based on the results of the MDS-003 trial, that lenalidomide may trigger progression to AML in some patients with del(5q).

Current recommendation state that treatment with lenalidomide in del(5q) MDS should be continued until disease progression [123]. The question whether interrruption of lenalidomide treatment for patients in remission would be beneficial has been also addressed [124]. It is important for several reasons: 1) it could reduce costs and side effects; 2) it could facilitate disease progression to AML. Different mechanisms have been discussed to explain AML progression. Evidence that pre-therapeutic telomere length was significantly shorter in those patients who ultimately transformed to AML than in those who did not was presented [125]. Transformation to AML is occasionally observed, paticularly in patients without a cytogenetic response to lenalidomide. Jädersten et al. [126] performed molecular studies in a patient with classical 5q- syndrome with complete erythroid and partial cytogenetic response to lenalidomide, who evolved to high-risk MDS with complex karyotype. Immunohistochemistry of pretreatment marrow biopsies revealed a small fraction of progenitors with overexpression of p53 and sequencing confirmed a TP53 mutation. TP53 mutated sub- 
clones have not previously been detected in 5q- syndrome and indicates heterogeneity of this disease. Subsequently, TP53 mutations with a median clone size of $11 \%$ (range, $1 \%$ to $54 \%)$ were detected in 10 from 55 (18\%) low-risk MDS or intermediate-1 risk patients with del(5q) by next-generation sequencing [127]. TP53 mutations are associated with strong nuclear p53 protein expression. Patients with mutation had significantly worse outcome. TP53 mutations may lead to genetic instability and disease progression. This clonal heterogeneity in low-risk MDS patients with del(5q) may be of importance when assessing the prognosis and selecting the therapy in these patients. It has been speculated that continuous administration of lenalidomide may lead to selective pressure on stem cells that induces genomic instability, resulting in acute leukemia transformation [128].

Longest transfusion-free intervals are achieved in patients low-risk MDS patients with del(5q) who are exposed to lenalidomide 6 months beyond complete cytogenetic remission [41, 124]. Lenalidomide should not be withdrawn prematurely in patients who achieve transfusion independence as partial cytogenetic remission patients seem to have a higher relapse rate than complete cytogenetic remission patients.

Treatment by lenalidomide is based on scientific knowledge because small deletions in several ribosomal genes, including RPS14, were found in CD34+ cells not only in patients with del(5q) but also in patients with non-del(5q) MDS [41, 42, 129-131]. This observation suggested that deregulated ribosomal biogenesis may not be limited to del $(5 q)$ MDS. Czibere et al. [132] showed that lower risk non-del(5q) MDS patients with RPS14 haploinsufficiency tend to have prolonged survival. Defective ribosomal biogenesis has a lead role in disrupting erythropoiesis in a variety of anemias. Disruption of ribosomal biogenesis has been clearly demonstrated in multiple ribosomopathies to greatly perturb p53 signaling [130, 131].

Bone marrow aspirates of patients who responded to lenalidomide showed before treatment decreased expression of the set of the genes needed for erythroid differentiation. Lenalidomide seems to overcome differentiation block in del(5q) patients with decreased expression of these genes compared to the non-responders [131]. Thus, lenalidomide restored erythroid differentiation potential by upregulation of the suppressed erythroid gene signature (genes for $\alpha$ - and $\beta$-globin, ankyrin 1, band 3, band 4.2, carbonic anhydrase, ferrochelatase and glycophorin B) [133].

The "Groupe Francophone des Myélodysplasies" conducted a multicenter phase 2 trial with lenalidomide in intermediate-2 (19 patients) and high-risk MDS (28 patients) with $\operatorname{del}(5 q)$. Forty seven patients (24 males and 23 females, with a median age of 69 years, range, 36-84 years) were treated. Forty three patients of 47 patients had transfusion-dependent anemia. Patients received $10 \mathrm{mg}$ lenalidomide once daily orally during 21 days every 4 weeks. In patients without response after 8 weeks, the lenalidomide dose was increased to $15 \mathrm{mg} /$ day in the same time schedule during an additional 8 weeks. If no response was found in this additional time of treatment, lenalidomide was discontinued. Thirteen of the 47 patients (27\%) achieved response according to International Working Group (IWG) 2006 criteria. Median duration of overall response was 6.5 months, 11.5 months in patients who achieved the complete remission. Grade 3 and 4 neutropenia and thrombocytopenia were seen in most patients. 
Möllgård et al. [7] hypothesized that increasing doses of lenalidomide may be successfully used in high-risk MDS and AML with chromosome 5 abnormalities. They tested this hypothesis in prospective phase II multicenter trial with 28 patients (12 with intermediate-risk 2 or high-risk MDS and 16 with AML). Oral lenalidomide was given at a dose of $10 \mathrm{mg} /$ day in weeks 1 to 5 . The dose was increased to $20 \mathrm{mg} /$ day in weeks 6 to 9 , and to $30 \mathrm{mg} / \mathrm{day}$ in weeks 10 to 16. In the case of suspected drug-related toxicity the dose was lowered to $5 \mathrm{mg} /$ day. The overall response rate in treated patients with MDS was 36\% (4/11) and that for AML patients was $20 \%$ (3/15). Seven patients stopped therapy due to progressive disease and nine because of complications, most of which were disease-related. Patients with TP53 mutations responded less well than those without mutations. No responses were observed among 11 cases with deleterious TP53 mutation [7].

\section{Randomized phase III placebo-controlled study of lenalidomide in $\operatorname{del}(5 q)$ patients}

This study [134] examined the safety of lenalidomide in a randomized phase III trial (MDS-004) in low-/int-1-risk myelodysplastic syndromes (MDS) with a del(5q) abnormality.

The similar criteria as in the MDS-003 study were chosen. Two hundred five patients were randomized to receive treatment with either lenalidomide $10 \mathrm{mg}$ orally daily for 21 days of each 28-day cycle, lenalidomide $5 \mathrm{mg}$ orally daily for 28 days of each 28-day cycle, or placebo. Erythroid responses were assessed at 16 weeks. Nonresponders were then in open-label treatment and they were excluded from the efficacy analysis. Red blood cell transfusion independence was achieved in $53.6 \%$ of patients treated on $10 \mathrm{mg}$ arm, 33.3\% on $5 \mathrm{mg}$ arm and $6 \%$ on the placebo arm. Cytogenetic response rates were also highest in the $10 \mathrm{mg}$ arm (41.5\% of patients), while in $5 \mathrm{mg}$ arm $(17.4 \%)$ and in the placebo arm $(0 \%)$. The median rise in hemoglobin at the time of the best response was also higher in patients treated with the $10 \mathrm{mg}$ lenalidomide. No difference in the rate of AML trandsformation among three arms was found. This study confirmed that the preferred starting dose of lenalidomide in patients with del(5q) low-/int-1-risk MDS remains $10 \mathrm{mg}$.

\section{Further clinical studies of lower risk MDS patients with del(5q) treated with lenalidomide}

Many of the initial clinical and laboratory observations obtained in the MDS-003 trial were confirmed in the study of Le Bras et al. [135]. Ninety five lower risk MDS patients (low and intermediate 1 risk in IPSS, 25 males and 70 females with a median age of 70.4 years) with del(5q) were treated with $10 \mathrm{mg}$ of lenalidomide daily, 21 days every 28 days for at least 16 weeks. Patients with at least a minor erythroid response after 16 weeks were treated in the same way until disease progression, treatment failure or treatment-limiting toxicity. 
Erythroid response was evaluated according to international working group (IWG) 2000 criteria. Sixty two of the 95 patients (65\%) achieved erythroid response according to IWG 2006 criteria. In these 62 patients, 60 patients (63\% from 95 patients) achieved red blood cell transfusion independence. Median time to transfusion independence was 16 weeks (range 8-33 weeks). Fifteen patients who achieved transfusion independence were analyzed for cytogenetic response ( $20 \%$ of complete and $40 \%$ of partial cytogenetic response). The rest of these 15 patients $(40 \%)$ had no cytogenetic response. Six (6.3\%) patients progressed to AML and 15 patients died, including 6 patients who had achieved transfusion independence. In the MDS-003 trial, the primary endpoint was hematological response, while in the study of Le Bras et al. transfusion independence. The cytogenetic remission rate was higher in the MDS-003 trial (73\% versus $60 \%$ in the study of Le Bras et al. [135]. Neutropenia and thrombocytopenia were the most common adverse events in both studies.

A Japanese multiinstitutional study MDS-007 in MDS patients with del(5q) treated with lenalidomide has been recently performed. This study was targeted on morphologic analysis and evaluation of the relationship among erythroid response, change of morphologic findings and cytogenetic response. MDS-007 trial was a single-arm, open-label study. Eleven patients were enrolled in this study, including 5 patients with transfusion-dependent anemia and 6 patients with transfusion-independent symptomatic anemia. Nine patients showed less than $25 \%$ of bone marrow erythroblasts before therapy with lenalidomide and no patient had more than $40 \%$ of bone marrow erythroblasts at that time. Eight patients showed a rapid increase of bone marrow erythroblasts to more than $40 \%$ on day 85 . All patients except one achieved a major erythroid response as defined by either transfusion independence or by rapid increase of hemoglobin level in most patients on day 169 of lenalidomide therapy. One patient without any hematologic response by day 169, achieved a major erythroid response on day 218. Erythroid response could be achieved even without a cytogenetic response. No patient in this analysis showed a hematological relapse prior to cytogenetic one. These findings suggested that lenalidomide can improve anemia by more than one mechanism of action and also through mechanism different from del(5q) elimination.

\section{Therapy with lenalidomide in combination with another drug in MDS}

In order to maximize the potential benefit from lenalidomide therapy combination strategies were developed. Lenalidomide in attemp to improve outcome of patients can be combined with erythropoiesis-stimulating agents (ESA), such as erythropoietin or darbepoietin alpha. This therapy is based on preclinical observations shoving that lenalidomide significantly potentiated erythropoietin receptor signaling. The addition of erythropoietin (40, $000 \mathrm{U} /$ week) for an additional 8-week course had the beneficial effect in low and intermediate-1 risk MDS patients who had failed prior treatment with lenalidomide monotherapy for 16 weeks. To evaluate the potential benefit of the combination of lenalidomide and ESA, Park et al. [136] tried the association in three del5q MDS patients, who were resistant or partially responding to lenalidomide alone. Lenalidomide had two different actions, one on the disapperance of 
the $5 \mathrm{q}$ - clone and the other one on the stimulation of the erythroid production in combination with ESA.

In low to intermediate-1 risk non-del(5q) MDS, lenalidomide treatment is less effective with a lower response rate $(25 \%)$ and shorter response duration than in the same risk MDS with $\operatorname{del}(5 q)$ [41]. Combination of lenalidomide with another drug could improve outcome of patients with low to intermediate-1 risk non-del(5q) MDS. Ezatiostat hydrochloride (Telintra, TLK199), a tripeptide glutathione analog is a reversible inhibitor of the enzyme glutathione S-transferase P1-1 (GSTP1-1) inhibitor. This inhibitor was developed for the treatment of cytopenias associated with lower risk MDS. Ezatiostat activates jun-N-terminal kinase (JNK), promoting the growth and maturation of hematopoietic progenitors, while inducing apoptosis in human leukemia blasts. The ability of ezatiostat to activate the caspase-dependent pathway may help eliminate or inhibit the emergence of malignant clones. Alternatively, ezatiostat increases reactive oxygen species in dysplastic cells and contibutes by this effect also to apoptotic death. Based on these mechanisms of action, response rates, non-overlapping toxicities, and tolerability observed in a single agent ezatiostat phase 1 and 2 studies in MDS, a study of the combination of ezatiostat and lenalidomide was conducted to determine the safety and efficacy of ezatiostat with lenalidomide in non-del(5q) low to intermediate- 1 risk MDS. Eighteen patients (median age 73 years; range 57-82; 72\% male) were enrolled in the study. Thirteen patients (72\%) were intermediate- 1 risk and 5 patients $(28 \%)$ were low risk. Four patients had abnormal cytogenetics. Twelve patients $(67 \%)$ were red blood cell transfusion-dependent and 2 patients (11\%) were were platelet transfusion-dependent. Three of $8(38 \%)$ patients achieved transfusion independence including 1 responder who did not respond to prior lenalidomide. Ezatiostat caused clinically significant reduction in red blood cell and platelet transfusions. Since ezatiostat is non-myelosuppressive, it is a good candidate for combination with lenalidomide. The recommended doses of this combination regimen for future studies is the ezatiostat.

Lenalidomide and azacitidine combination has been already described [14, 114].

Romiplostim (AMG 531, Nplate) is an Fc-peptide fusion protein (peptibody) that acts as a thrombopoietin receptor agonist. It has no amino acid sequence homology with endogenous thrombopoietin. Romiplostim stimulates megakaryopoiesis and thrombopoiesis by binding to and activating the thrombopoietin receptor and downstream signaling. Romiplostim appeared well tolerated in patients with lower risk MDS and thrombocytopenia. Low platelet counts in patients with MDS may be due to the underlying disease or due to treatment with disease-modifying agents, and platelet transfusions are often the only treatment for clinically significant thrombocytopenia or bleeding. Randomized phase II study evaluating the efficacy and safety of romiplostim treatment of patients with low or intermediate- 1 risk MDS receiving lenalidomide was performed. This was double-blind, placebo controlled, dose finding study that evaluated the effect of romiplostim on the incidence of clinically significant thrombocytopenia events (grade 3 or 4 thrombocytopenia and/or receipt of platelet transfusions) and the safety of romiplostim in patients with low or intermediate-1 risk MDS receiving lenalidomide. Thirty nine patients (median age 74 years; range, 39 to 90) were randomized into treatment groups receiving placebo, $500 \mu \mathrm{g}$ romiplostim, or $750 \mu \mathrm{g}$ romi- 
plostim by weekly subcutaneous injections in combination with lenalidomide (one $10 \mathrm{mg}$ capsule by mouth daily for each 28-day cycle). Fifteen patients (39\%) had platelet

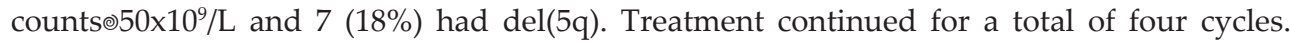
Twelve patients (31\%) discontinued the study. Disease progression to AML was reported in 1 patient in the romiplostim $500 \mu \mathrm{g}$ group. Response was $8 \%$ for the placebo, $36 \%$ for $500 \mu \mathrm{g}$ romiplostim, and $15 \%$ for $750 \mu \mathrm{g}$ romiplostim groups. Romiplostim appeared to be well tollerated in low or intermediate-1 risk MDS patients receiving lenalidomide.

It is possible that effect of lenalidomide could be augmented with the addition of another immunomodulation agent, cyclosporine A. A single-arm, open-label study of the efficacy and safety of lenalidomide in combination with cyclosporine A in red blood cell transfusion-dependent both 5q- and non 5q- MDS patients started at Weill Cornell Medical College in New York.

Other drugs are tried and will be probably used in combinations with lenalidomide in the treatment MDS patients with $\operatorname{del}(5 \mathrm{q})$ in the future. Dexamethasone and lenalidomide rescue erythropoiesis, alone and in combination, in RPS14- and RPS19- (ribosomal proteins of small ribosomal subunit) deficient cells [137]. L-leucine was also studied in RPS14- and RPS19- deficient cells [138-141]. The combined use of L-leucine and lenalidomide might be considered for therapy in MDS patients with the $\operatorname{del}(5 q)$ since there is evidence to suggest that these two drugs act through different mechanism and their effect may be synergistic.

\section{Mechanisms of action of lenalidomide}

Lenalidomide shares a number of structural and biological properties with thalidomide but is safer and more potent than thalidomide. Both drugs appear to function through four mechanisms: immunomodulatory, anti-inflammatory, anti-angiogenic and direct neoplastic cells inhibitory [41, 42, 142]. Lenalidomide has a direct erythropoiesis stimulating effect. Wei et al. [143] demonstrated that the haplodeficient enzymatic targets of lenalidomide within the commonly deleted region are two dual-specificity phosphatases, the cell division cycle 25C (Cdc25C) and the protein phosphatase 2A (PP2A). These phosphatases are coregulators of G2-M checkpoint in the cell cycle and thus, their inhibition by lenalidomide leads to $\mathrm{G} 2$ arrest and apoptosis of $\operatorname{del}(5 \mathrm{q})$ specimens. The mechanism of action is different in non-del(5q), where lenalidomide restores and promotes effective erythropoiesis with no direct cytotoxic effect [144]. Lenalidomide promotes erythropoiesis and fetal hemoglobin production in human CD34+ cells [144]. The increased fetal hemoglobin expression was associated with epigenetic effect on chromatin (an increase in histone 3 acetylation on the $\gamma$-globin gene promoter).

The similar epigenetic modulation of gene for p21(CIP1/WAF1) by lenalidomide was described in both lymphoma and multiple myeloma. A potent cyclin-dependent kinase inhibitor p21(CIP1/WAF1) decreases activity of cyclinE-CDK2 or cyclinD-CDK4/6 complexes, and thus functions as a regulator of cell cycle progression. The p21 protein can mediate cellular senescence and also interact with proliferating cell nuclear antigen (PCNA), a DNA poly- 
merase accessory factor, and plays a regulatory role in S phase DNA replication and DNA damage repair.

Most MDS patients including those with $\operatorname{del}(5 q)$ become refractory to erythropoietin (EPO). EPO is an essential glycoprotein that facilitates red blood cell maturation from erythroid progenitors and mediates erythropoiesis. EPO acts through EPO-receptor (EPO-R) and the signal transducer and activator of transcription 5 (STAT5). Disruption of STAT5 results in a variety of cell-specific effects, one of which is the impaired erythropoiesis. Lenalidomide relieves repression of ligand-dependent activation of the EPO-R/STAT5 pathway. Ebert et al. [133] showed that target genes of this pathway are underexpressed in lenalidomide-responsive MDS patients wihout del (5q). Lenalidomide promotes erythropoiesis in MDS by CD45 protein tyrosine phosphatase inhibition. CD45 phosphatase is overactivated in MDS and may inhibit phosphorylation of STAt5 stimulated by EPO-R. Lenalidomide is able to restore EPO-R/STAT5 signaling that is essential for hematopoiesis. Lenalidomide restores and promotes effective erythropoiesis in non-del(5q) without direct cytotoxic effect.

A deregulated immune system plays the important role in pathogenesis of MDS. Deregulation is caused by the alteration of cytokines in the bone marrow microenvironment, deffective T-cell regulation and diminished natural killer (NK) cell activity. Deficiences in T cells, NK cells and interferon- $\gamma($ IFN- $\gamma)$ production were described in the bone marrow and peripheral blood of MDS patients. Lenalidomide exhibits potent T-cell costimulatory properties and augmented production of IL-2 and IFN- $\gamma$ [118]. Akt (proteinase B) signaling pathway and transcription factor AP1 (activator protein 1) are involved in T-cell activation. Increased numbers and activation of NK and NK T-cell populations were also observed in peripheral blood cells cultured with lenalidomide.

Anti-inflammatory effects of lenalidomide is based on the inhibition of proinflammatory cytokines and chemokines, such as TNF- $\alpha$, IL-1 $\beta$, IL- 6 , IL-12, monocyte chemotactic protein- 1 and macrophage inflammatory protein- $1 \alpha$. On the other hand, lenalidomide elevates antiinflammatory cytokine IL-10. Interestingly, haploinsuficiency of miR-145 and miR-146a in $5 q$ - syndrome increases IL-6 levels by elevation of interleukin-1 receptor-associated kinase 1 (IRAK1), Toll-interleukin-1 receptor domain-containing adaptor protein (TIRAP), tumor necrosis factor receptor-associated factor-6 (TRAF6), and NF- $\kappa B$ [145].

Angiogenesis, the formation of new blood vessels, plays an important role in the growth and progression of MDS. Anti-angiogenic effects of lenalidomide are independent of immunomodulatory effects and are mediated through endothelial cell migration inhibition. The mechanism by which lenalidomide inhibited vascular endothelial growth factor (VEGF)-induced endothelial cell migration may be related to VEGF-induced inhibition of Akt phosphorylation. Furthermore, loss of anti-angiogenic effect of lenalidomide predicted disease progression and an increased risk of transformation to AML.

Lenalidomide does not affect DNA synthesis but inhibits cytokinesis of MDS cells. Cytokinesis occurs as the final stage of cell division after mitosis. A contractile ring, made of nonmuscle myosin and actin filaments assembles in the middle of the cell adjacent to the cell membrane. Formins are Rho-GTPase effector proteins that are involved in the polymeriza- 
tion of actin and effects microtubule during meiosis, mitosis, the maintenance of cell polarity, vesicular trafficking and signaling to the nucleus. Diaphanous (mDia)-related formin mDia1 is encoded by DIAPH1 located on the long arm of chromosome 5 (5q31.3) and lies between the two commonly deleted regions in MDS patients with $5 q$ - syndrome. It is not clear whether mDia1 plays a role in lenalidomide effect on cytokinesis. Knock-out of DIAPH1 in mice has $\mathrm{T}$ cell responses and myelodysplastic phenotype.

The clinical effect of lenalidomide is associated with significant increases in the numbers of erythroid, myeloid and megakaryocytic colony-forming cells and a substantial improvement in the hematopoiesis-supporting capacity of bone marrow stroma. Lenalidomide induces significant alterations in the adhesion profile of hematopoietic progenitor cells, including over-expression of membrane ligands (CXCR4/CD184, CD54/ICAM1, CD11a and CD49d where $\mathrm{CD}$ is cluster of differentiation) and overproduction of soluble stromal cell-derived factor-1 (SDF-1) and of ICAM1 in the bone marrow microenvironment. CXCR4 is C-X-C chemokine receptor type 4 also known as fusin or CD184. ICAM1 (intracellular adhesion molecule 1 also known as CD54) is a cell surface glycoprotein. All these effects favor the maintenance of CD34+ cells in the bone marrow. Lenalidomide-mediated induction of the SLAM antigen CD48 on patients' CD34+ cells may be associated with the drug's apoptosisinducing effect through co-stimulatory interactions between CD34+ cells and cytotoxic lymphocytes in the bone marrow microenvironment.

\section{Conclusion and perspectives}

Despite the encouraging results with azacitidine and decitabine, it is obvious that it will be important to have access to second generation agents with the capacity to increase faster early response rates with acceptable toxicity profiles. Preliminary results with oral formulation of both azacitine and decitabine are promising and these forms could improve hypomethylating therapy of MDS patients in future. Another approach is to develop combination strategies using either azacitidine or decitabine. Several such approaches are currently studied and many are promising but not yet fully understood. Including of cytidine deaminase inhibitor in these combinations appears to be important for better results but it needs new clinical studies. Lenalidomide is currently the treatment of choice for lower risk transfusiondependent $\operatorname{del}(5 q)$ MDS patients, and remains a treatment alternative for the management of anemia in lower risk MDS without $5 q$ deletion MDS patients with adequate neutrophil and platelet counts [41, 42]. Lenalidomide has also activity in higher risk MDS and AML with del(5q) and even in non(del5q) MDS.

Though the mechanism of lenalidomide action has not been definitively determined, it is clear that there is difference between mechanisms in MDS with del(5q) and MDS with non-del(5q).

In MDS with del(5q), lenalidomide acts through inhibition of phosphatase activity in the commonly deleted region of the long arm of chromosome 5. This phosphatases play a key role in in cell cycle regulation. The inhibition of these phosphatases by lenalidomide leads to G2 arrest, followed by apoptosis of $\operatorname{del}(5 \mathrm{q})$ specimens. The direct cytotoxic effects of lenali- 
domide on the del(5q) clone are also very important. Lenalidomide inhibits the malignant clone and up-regulates the SPARC gene mapping to the commonly deleted region in 5qsyndrome patients. However, SPARC is dispensable for murine hematopoiesis [146]. While haploinsufficiency of the RPS14 gene appears to be a key contributor to erythropoietic failure associated with del(5q) MDS, the critical genes responsible for clonal dominance in $\operatorname{del}(5 q)$ high-risk MDS and AML are less well-defined. It is known that this deleted region is different in del(5q) high-risk MDS and AML [147]. The effect of lenalidomide in these cases needs to identify further biologic features accounting for response, thereby allowing rational use of this drug, both alone and in combination with another agents.

In MDS with non-del(5q), an increased expression of adhesion molecules caused by lenalidomide treatment leads to recovery and maintenance of the CD34+ cells through interactions between the hematopoietic and stromal cells. This effect of lenalidomide on the bone marrow microenvironment causes abrogation of the function of pro-apoptotic and pro-inflammatory cytokines. Lenalidomide is capable to increase red blood cell production independently of ribosome dysfunction. Lenalidomide restores and promotes effective erythropoiesis without direct cytotoxic effect. Lenalidomide activates the EPO-R/STAT5 pathway.

New cytogenetic tools such as fluorescence in situ hybridization (FISH) or single nucleotide polymorphism array (SNP-A)-based karyotyping increased the diagnostic yield over metaphase cytogenetics. Sugimoto et al. [148] have recently found with help of these new cytogenetic tools that normal karyotype and gain of chromosome 8 were predictive of response to lenalidomide in non-del(5q) patients with myeloid malignancies.

The presence of multiple cellular and genetic abnormalities in MDS and AML is common and suggests that combination therapy targeting different mechanisms of action may be beneficial particularly in higher-risk MDS disease, for which both microenvironment and cell regulatory mechanisms play a role. The optimal dose, schedule and duration of treatment is still an area of active investigation, especially in the use of lenalidomide combinations with other drugs.

\section{Acknowledgements}

This work was supported by the research grant NT/13836-4/2012 from the Ministry of Health of the Czech Republic.

\section{Author details}

Ota Fuchs*

Address all correspondence to:

Institute of Hematology and Blood Transfusion, Prague, Czech Republic 


\section{References}

[1] Tone, R.M. (2009). How I treat patients with myelodysplastic syndromes. Blood, 113(25), 6296-6303.

[2] Fehniger, T. A., Byrd, J. C., Marcucci, G., Abboud, C. N., Kefauver, C., Payton, J. E., Vij, R., \& Blum, W. (2009). Single-agent lenalidomide induces complete remission of acute leukemia in patiens with isolated trisomy 13. Blood, 113(5), 1002-1005.

[3] Fenaux, P., Bowen, D., Gattermann, N., Hellström-Lindberg, E., Hofmann, W. K., Pfeilstöcker, M., Sanz, G., \& Santini, V. (2010). Practical use of azacitidine in higherrisk myelodysplastic syndromes: An expert panel opinion. Leukemia Research, 34(11), 1410-1416.

[4] Fenaux, P., Mufti, G. J., Hellström-Lindberg, E., Santini, V., Gattermann, N., Germing, U., Sanz, G., List, A. F., Gore, S., Seymour, J. F., Dombret, H., Backstrom, J., Zimmerman, L., Mc Kenzie, D., Beach, C. L., \& Silverman, L. R. (2010). Azacitidine prolongs overall survival compared with conventional care regimens in elderly patients with low bone marrow blast count acute myeloid leukemia. Journal of Clinical Oncology, 28(4), 562-569.

[5] Cashen, A. F., Schiller, G. J., O', Donnell. M. R., \& Di Persio, J. F. (2010). Multicenter, phase II study of decitabine for the first-line treatment of older patients with acute myeloid leukemia. Journal of Clinical Oncology, 28(4), 556-561.

[6] Abujamra, A. L., Dos, Santos. M. P., Roesler, R., Schwartsmann, G., \& Brunetto, A. L. (2010). Histone deacetylase inhibitors: A new perspective for the treatment of leukemia. Leukemia Research, 34(6), 687-695.

[7] Möllgård, L., Saft, L., Treppendahl, M. B., Dybedal, I., Nørgaard, J. M., Astermark, J., Ejerblad, E., Garelius, H., Dufva, I. H., Jansson, M., Jädersten, M., Kjeldsen, L., Linder, O., Nilsson, L., Vestergaard, H., Porwit, A., Grønbaek, K., \& Hellström-Lindberg, E. (2011). Clinical effect of increasing doses of lenalidomide in high-risk myelodysplastic syndrome and acute myeloid leukemia with chromosome 5 abnormalities. Haematologica, 96(7), 963-971.

[8] Fehniger, T. A., Uy, G. L., Trinkaus, K., Nelson, A. D., Domland, J., Abboud, C. N., Cashen, A. F., Stockerl-Goldstein, K. E., Westervelt, P., Di Persio, J. F., \& Vij, R. (2011). A phase 2 study of high-dose lenalidomide as initial therapy for older patients with acute myeloid leukemia. Blood, 117(6), 1828-1833.

[9] Sekeres, M. A., Gundacker, H., Lancet, J., Advani, A., Petersdorf, S., Liesveld, J., Mulford, D., Norwood, T., Willman, C. L., Appelbaum, F. R., \& List, A. F. (2011). A phase 2 study of lenalidomide monotherapy in patients with deletion $5 q$ acute myeloid leukemia: Southwest Oncology Group Study S0605. Blood, 118(3), 523-528.

[10] Prebet, T., \& Vey, N. (2011). Vorinostat in acute myeloid leukemia and myelodysplastic syndromes. Expert Opinion on Investigational Drugs, 20(2), 287-295. 
[11] Quintás-Cardama, A., Santos, F. P., \& Garcia-Manero, G. (2011). Histone deacetylase inhibitors for the treatment of myelodysplastic syndrome and acute myeloid leukemia. Leukemia, 25(2), 226-235.

[12] Ornstein, M. C., \& Sekeres, M. A. (2012). Combination strategies in myelodysplastic syndromes. International Journal of Hematology, 95(1), 26-33.

[13] Ozbalak, M., Cetiner, M., Bekoz, H., Atezoglu, E. B., Ar, C., Salihoglu, A., Tuzuner, N., \& Ferhanoglu, B. (2012). Azacitidine has limited aktivity in 'real life' patiens with MDS and AML: a single centre experience. Hematological Oncology, 30(2), 76-81.

[14] Pollyea, D. A., Kohrt, H. E., Gallegos, L., Figueroa, M. E., Abdel-Wahab, O., Zhang, B., Battacharya, S., Zehnder, J., Liedtke, M., Gotlib, J. R., Coutre, S., Berube, C., Melnick, A., Levine, R., Mitchell, B. S., \& Medeiros, B. C. (2012). Safety, efficacy and biological predictors of response to sequential azacitidine and lenalidomide for elderly patients with acute myeloid leukemia. Leukemia,, 26(5), 893-901.

[15] Schecter, J., Galili, N., \& Raza, A. (2012). MDS: Refining existing therapy through improved biologic insights. Blood Reviews, 26(2), 73-80.

[16] Fazi, F., Racanicchi, S., Zardo, G., Starnes, L. M., Mancini, M., Travaglini, L., Diverio, D., Ammatuna, E., Cimino, G., Lo-Coco, F., Grignani, F., \& Nervi, C. (2007). Epigenetic silencing of the myelopoiesis regulator microRNA-223 by the AML1/ETO oncoprotein. Cancer Cell, 12(5), 457-466.

[17] Nervi, C., Fazi, F., \& Grignani, F. (2008). Oncoproteins, heterochromatin silencing and microRNAs: a new link for leukemogenesis. Epigenetics, 3(1), 1-4.

[18] Garzon, R., Lin, S., Fabbri, M., Liu, Z., Heaphy, C. E., Callegari, E., Schwind, S., Pang, J., Yu, J., Muthusamy, N., Havelange, V., Volinia, S., Blum, W., Rush, L. J., Perrotti, D., Andreeff, M., Bloomfield, C. D., Byrd, J. C., Chan, K., Wu, L. C., Croce, C. M., \& Marcucci, G. (2009). MicroRNA-29b induces global DNA hypomethylation and tumor suppressor gene reexpression in acute myeloid leukemia by targeting directly DNMT3A and 3B and indirectly DNMT1. Blood, 113(25), 6411-6418.

[19] Sato, F., Tsuchiya, S., Meltzer, S. J., \& Shimizu, K. (2011). MicroRNAs and epigenetics. FEBS Journal, 278(10), 1598-1609.

[20] Chim, C. S., Wong, K. Y., Leung, C. Y., Chung, L. P., Hui, P. K., Chan, S. Y., \& Yu, L. (2011). Epigenetic inactivation of the has-miR-203 in haematological malignancies. Journal of Cellular and Molecular Medicine, 15(12), 2760-2767.

[21] Wong, K. Y., So, C. C., Loong, F., Chung, L. P., Lam, W. W., Liang, R., Li, G. K., Jin, D. Y., \& Chim, C. S. (2011). Epigenetic inactivation of the miR-1241in haematological malignancies. PLOS One 6 (4): e 19027.

[22] Rager, J. E., \& Fry, R. C. (2012). The aryl hydrocarbon receptor pathway: a key component of the microRNA-mediated AML signalisome. International Journal of Environmental Research and Public Health, 9(5), 1939-1953. 
[23] Kantarjian, H., Issa, J. P., Rosenfeld, C. S., Bennett, J. M., Albitar, M., Di Persio, J., Klimek, V., Slack, J., de Castro, C., Ravandi, F., \& Helmer, R. (2006). 3rd, Shen L, Nimer SD, Leavitt R, Raza A, Saba H. Decitabine improves patient outcomes in myelodysplastic syndromes: results of a phase III randomized study. Cancer, 106(8), 1794-1803.

[24] Issa, J. P., \& Kantarjian, H. M. (2009). Targeting DNA methylation. Clinical Cancer Research, 15(12), 3938-3946.

[25] Lübbert, M., Suciu, S., Baila, L., Rüter, B. H., Platzbecker, U., Giagounidis, A., Selleslag, D., Labar, B., Germing, U., Salih, H. R., Beeldens, F., Muns, P., Pflüger, K. H., Coens, C., Hagemeijer, A., Eckart, Schaefer. H., Ganser, A., Aul, C., de Witte, T., \& Wijermans, P. W. (2011). Low-dose decitabine versus best supportive care in elderly patiens with intermediate- or high-risk myelodysplastic syndrome (MDS) ineligible for intensit chemotherapy: final results of the randomized phase III study of the European Organisation for Research and Treatment of Cancer Leukemia Group and the German MDS Study Group. Journal of Clinical Oncology, 29(15), 1987-1996.

[26] Estey E.H. (2012). Acute myeloid leukemia: update on diagnosis, risk stratification, and management. American Journal of Hematology 2012, 87(1), 89-99.

[27] Garcia-Manero, G. (2012). Myelodysplastic syndromes: 2012 update on diagnosis, risk stratification, and management. American Journal of Hematology, 87(7), 692-701.

[28] Keating, G.M. (2012). Azacitidine: a review of its use in the management of myelodysplastic syndromes/ acute myeloid leukaemia. Drugs, 72(8), 1111-1136.

[29] Al-Ali, H. K., Jaekel, N., Junghanss, C., Maschmeyer, G., Krahl, R., Cross, M., Hoppe, G., \& Niederwieser, D. (2012). Azacitidine in patients with acute myeloid leukemia medically unfit for or resistant to chemotherapy: a multicenter phase I/II study. Leukemia and Lymphoma, 53(1), 110-117.

[30] Marks, P.W. (2012). Decitabine for acute myeloid leukemia. Expert Review of Anticancer Therapy, 12(3), 299-305.

[31] Itzykson, R., \& Fenaux, P. (2012). Optimizing hypomethylating agents in myelodysplastic syndromes. Current Opinion of Hematology, 19(2), 65-70.

[32] Blum, W., Garzon, R., Klisovic, R. B., Schwind, S., Walker, A., Geyer, S., Liu, S., Havelange, V., Becker, H., Schaaf, L., Mickle, J., Devine, H., Kefauver, C., Devine, S. M., Chan, K. K., Heerema, N. A., Bloomfield, C. D., Grever, M. R., Byrd, J. C., VillalonaCalero, M., Croce, C. M., \& Marcucci, G. (2010). Clinical response and miR-29b predictive significance in older AML patients treated with a 10-day schedule of decitabine. Proceedings of the National Academy of Sciences of the United States of America, 107(16), 7473-7478.

[33] Lübbert, M., Rüter, B. H., Claus, R., Schmoor, C., Schmid, M., Germing, U., Kuendgen, A., Rethwisch, V., Ganser, A., Platzbecker, U., Galm, O., Brugger, W., Hell, G., Hackanson, B., Deschler, B., Döhner, K., Hagemeijer, A., Wijermans, P. W., \& Döhner, H. (2012). A multicenter phase II trial of decitabine as first-line treatment for old- 
er patiens with acute myeloid leukemia judged unfit for induction chemotherapy. Haematologica, 97(3), 393-401.

[34] Kantarjian, H. M., Thomas, X. G., Dmoszynska, A., Wierzbowska, A., Mazur, G., Mayer, J., Gan, J. P., Chou, W. C., Buckstein, R., Cermak, J., Kuo, C. Y., Oriol, A., Ravandi, F., Faderl, S., Delaunay, J., Lysák, D., Minden, M., \& Arthur, C. (2012). Multicenter, randomized, open-label phase III trial of decitabine versus patient choice, with physician advice, of either supportive care of low-dose cytarabine for the treatment of older patients with newly diagnosed acute myeloid leukemia. Journal of Clinical Oncology published online before print on June 11 doi:JCO.2011.38.9429.

[35] Negrotto, S., Ng, K. P., Jankowska, A. M., Bodo, J., Gopalan, B., Guinta, K., Mulloy, J. C., Hsi, E., Maciejewski, J., \& Saunthararajah, Y. (2012). CpG methylation patterns and decitabine treatment response in acute myeloid ledukemia cells and normal hematopoietic precursors. Leukemia, 26(2), 244-254.

[36] Fabiani, E., Leone, G., Giachelia, M., D', Alo'. F., Greco, M., Criscuolo, M., Guidi, F., Rutella, S., Hohaus, S., \& Voso, M. T. (2010). Analysis of genome-wide methylation and gene expression induced by 5-aza-2'-deoxycytidine identifies BCL2L10 as a frequent methylation target in acute myeloid leukemia. Leukemia and Lymphoma, 51(12), 2275-2284.

[37] Stresemann, C., Brueckner, B., Musch, T., Stopper, H., \& Lyko, F. (2006). Functional diversity of DNA methyltransferase inhibitors in human cancer cell lines. Cancer Research, 66(5), 2794-2800.

[38] Foulks, J. M., Parnell, K. M., Nix, R. N., Chan, S., Swierczek, K., Saunders, M., Wright, K., Hendrickson, T. F., Ho, K. K., Mc Cullar, M. V., \& Kanner, S. B. (2012). Epigenetic drug discovery: targeting DNA methyltransferases. Journal of Biomolecular Screening, 17(1), 2-17.

[39] Gore, S.D., \& Hermes-De Santis, E.R. (2008). Future directions in myelodysplastic syndrome: newer agents and the role of combination approaches. Cancer Control 15 (Suppl), 40-49.

[40] Goodyear, O., Agathanggelon, A., Novitzky-Basso, I., Siddique, S., Mc Skeane, T., Ryan, G., Vyas, P., Cavenagh, J., Stankovic, T., Moss, P., \& Craddock, C. (2010). Induction of a CD8+T-cell response to the MAGE cancer testis antigen by combined treatment with azacitidine and sodium valproate in patients with acute myeloid leukemia and myelodysplasia. Blood, 116(11), 1908-1918.

[41] Komrokji, R. S., \& List, A. F. (2010). Lenalidomide for treatment of myelodysplastic syndromes: current status and future directions. Hematology/Oncology Clinics of North America, 24(2), 377-388.

[42] Heise, C., Carter, T., Schafer, P., \& Chopra, R. (2010). Pleiotropic mechanisms of action of lenalidomide efficacy in del (5q) myelodysplastic syndromes. Expert Review of Anticancer Therapy, 10(10), 1663-1672. 
[43] Wei, S., Chen, X., Mc Graw, K., Zhang, L., Komrokji, R., Clark, J., Caceres, G., Billingsley, D., Sokol, L., Lancet, J., Fortenbery, N., Zhou, J., Eksioglu, E. A., Sallman, D., Wang, H., Epling-Burnette, P. K., Djeu, J., Sekeres, M., Maciejewski, J. P., \& List, A. (2012). Lenalidomide promotes 53degradation by inhibiting MDM2 auto-ubiquitination in myelodysplastic syndrome with chromosome 5q deletion. Oncogene 2012 published online before print on April 23 onc.2012.139.

[44] Rice, K. L., Hormaeche, I., \& Licht, J. D. (2007). Epigenetic regulation of normal and malignant hematopoiesis. Oncogene, 26(47), 6697-6714.

[45] Xu, F., Mao, C., Ding, Y., Rui, C., Wu, L., Shi, A., Zhang, H., Zhang, L., \& Xu, Z. (2010). Molecular and enzymatic profiles of mammalian DNA methyltransferases: structures and targets for drugs. Current Medicinal Chemistry, 17(33), 4052-4071.

[46] Jin, B., Li, Y., \& Robertson, K. D. (2011). DNA methylation: superior or subordinate in the epigenetic hierarchy. Genes and Cancer, 2(6), 607-617.

[47] Jurkowska, R. Z., Jurkowski, T. P., \& Jeltsch, A. (2011). Structure and function of mammalian DNA methyltransferases. ChemBioChem., 12(2), 206-222.

[48] Figueroa, M. E., Skrabanek, L., Li, Y., Jiemjit, A., Fandy, T. E., Paietta, E., Fernandez, H., Tallman, M. S., Greally, J. M., Carraway, H., Licht, J. D., Gore, S. D., \& Melnick, A. (2009). MDS and secondary AML display unique patterns and abundance of aberrant DNA methylation. Blood, 114(16), 3448-3458.

[49] Uchida, T., Kinoshita, T., Nagai, H., Nakahara, Y., Saito, H., Holta, T., \& Murate, T. (1997). Hypermethylation of the 15INK4Bgene in myelodysplastic syndromes. Blood 90 (4) 1403-1409.

[50] Quesnel, B., Guillerm, G., Verecque, R., Wattel, E., Preudhomme, C., Bauters, F., Vanrumbeke, M., \& Fenaux, P. (1998). Methylation of the 15INK4b) gene in myelodysplastic syndromes is frequent and acquired during disease progression. Blood 91 (8) 2985-2990.

[51] Tien, H. F., Tang, J. H., Tsay, W., Liu, M. C., Lee, F. Y., Wang, C. H., Chen, Y. C., \& Shen, M. C. (2001). Methylation of the $15 \mathrm{INK} 4 \mathrm{~b})$ gene in myelodysplastic syndrome: it can be detected early at diagnosis or during disease progression and is highly associated with leukaemic transformation. British Journal of Haematology 112 (1) 148-154.

[52] Christiansen, D. H., Andersen, M. K., \& Pedersen-Bjergaard, J. (2003). Methylation of 15INK4B) is common, is associated with deletion of genes on chromosome arm $7 \mathrm{q}$ and predicts a poor prognosis in therapy- related myelodysplasia and acute myeloid leukemia. Leukemia 17 (9) 1813-1819.

[53] Cechova, H., Lassuthova, P., Novakova, L., Belickova, M., Stemberkova, R., Jencik, J., Stankova, M., Hrabakova, P., Pegova, K., Zizkova, H., \& Cermak, J. (2012). Monitoring of methylation changes in 921region in patients with myelodysplastic syndromes and acute myeloid leukemia. Neoplasma 59 (2) 168-174. 
[54] Issa, J.P. (2010). Epigenetic changes in the myelodysplastic syndrome. Hematology/ Oncology Clinics of North America, 24(2), 317-330.

[55] Valencia, A., Cervera, J., Such, E., Ibanez, M., Gómez, I., Luna, I., Senent, L., Oltra, S., Sanz, M. A., \& Sanz, G. F. (2011). Aberrant methylation of tumor suppressor genes in patients with refractory anemia with ring sideroblasts. Leukemia Research, 35(4), 479-483.

[56] Yang, Y., Zhang, Q., Xu, F., Wu, L., He, Q., \& Li, X. (2012). Tumor suppressor gene BLU is frequently downregulated by promoter hypermethylation in myelodysplastic syndrome. Journal of Cancer Research and Clinical Oncology, 138(5), 729-737.

[57] Tran, H. T. T., Kim, H. N., Lee, I. K., Kim, Y. K., Ahn, J. S., Yang, D. H., Lee, J. J., \& Kim, H. J. (2011). DNA methylation changes following 5-azacitidine treatment in patients with myelodysplastic syndrome. Journal of Korean Medical Science, 26(2), 207-213.

[58] Graubert, T., \& Walter, M. J. (2011). Genetics of myelodysplastic syndromes: new insights. Hematology, 2011(543), 549.

[59] Fathi, A. T., \& Abdel-Wahab, O. (2012). Mutations in epigenetic modifiers in myeloid malignancies and the prospect of novel epigenetic-targeted therapy. Advances in Hematology 2012, 469592.

[60] Nikolski, G., van der Reijden, B.A., \& Jansen, J.H. (2012). Mutations in epigenetic regulators in myelodysplastic syndromes. International Journal of Hematology, 95(1), 8-16.

[61] McDevitt, M.A. (2012). Clinical applications of epigenetic markers and epigenetic profiling in myeloid malignancies. Seminars in Oncology, 39(1), 109-122.

[62] Varier, R. A., \& Timmers, H. T. (2011). Histone lysine methylation and demethylation pathways in cancer. Biochimica et Biophysica Acta, 1815(1), 75-89.

[63] Morishita, M., \& di Luccio, E. (2011). Cancers and the NSD family of histone lysine methyltransferases. Biochimica et Biophysica Acta, 1816(2), 158-163.

[64] Di Lorenzo, A., \& Bedford, M.T. (2011). Histone arginine methylation. FEBS Letters, 585(13), 2024-2031.

[65] Wei, Y., Gaňán, Gómez. I., Salazar-Dimicoli, S., Mc Cay, S. L., \& Garcia-Manero, G. (2011). Epigenomics, 3(2), 193-205.

[66] Shen, X., \& Orkin, S. H. (2009). Glimpses of the epigenetic landscape. Cell Stem Cell 4 (1), 1-2.

[67] Mochizuki-Kashio, M., Mishima, Y., Miyagi, S., Negishi, M., Saraya, A., Konuma, T., Shinga, J., Koseki, H., \& Iwama, A. (2011). Dependency on the polycomb gene Ezh2 distinguishes fetal from adult hematopoietic stem cells. Blood, 118(25), 6553-6561. 
[68] Agger, K., Cloos, P. A., Christensen, J., Pasini, D., Rose, S., Rappsilber, J., Issaeva, I., Canaani, E., Salcini, A. E., \& Helin, K. (2007). UTX and JMJD3 demethylases involved in HOX gene regulation and development. Nature, 449(7163), 731-734.

[69] Nikolski, G., Langemeijer, S. M., Kniper, R. P., Knops, R., Massop, M., Tönnissen, E. R., van der Heijden, A., Scheele, T. N., Vandenberghe, P., de Witte, T., van der Reijden, B. A., \& Jansen, J. H. (2010). Somatic mutations of the histone methyltransferase gene EZH2 in myelodysplastic syndromes. Nature Genetics, 42(8), 665-667.

[70] Xu, F., Li, X., Wu, L., Zhang, Q., Yang, R., Yang, Y., Zhang, Z., He, Q., \& Chang, C. (2011). Overexpression of the EZH2, RING1 and BMI1 genes is common in myelodysplastic syndromes: relation to adverse epigenetic alteration and poor prognostic scoring. Annals of Hematology, 90(6), 643-653.

[71] Szpurka, H., Jankowska, A. M., Przychodzen, B., Hu, Z., Saunthararajah, Y., Mc Devitt, M. A., \& Maciejewski, J. P. (2010). UTX mutations and epigenetic changes in MDS/MPN and related myeloid malignancies. Blood (ASH Annual Meeting Abstracts) 116 (21) 121.

[72] Jankowska, A. M., Makishima, H., Tiu, R. V., Szpurka, H., Huang, Y., Traina, F., Visconte, V., Sugimoto, Y., Prince, C., O', Keefe. C., His, E. D., List, A., Sekeres, M. A., Rao, A., Mc Devitt, M. A., \& Maciejewski, J. P. (2011). Mutational spectrum analysis of chronic myelomonocytic leukemia includes genes associated with epigenetic regulation: UTX, EZH2, and DNMT3A. Blood, 118(14), 3932-3941.

[73] Jankowska, A. M., \& Szpurka, H. (2012). Mutational determinants of epigenetic instability in myeloid malignancies. Seminars in Oncology, 39(1), 80-96.

[74] Glozak, M. A., \& Seto, E. (2007). Histone deacetylases and cancer. Oncogene, 26(37), 5420-5432.

[75] Yang, X. J., \& Seto, E. (2007). HATs and HDACs: from structure, function and regulation to novel strategies for therapy and prevention. Oncogene, 26(37), 5310-5318.

[76] Rasheed, W. K., Johnstone, R. W., \& Prince, H. M. (2007). Histone deacetylase inhibitors in cancer therapy. Expert Opinion on Investigational Drugs, 16(5), 659-678.

[77] Dokmanovic, M., Clarke, C., \& Marks, P. A. (2007). Histone deacetylase inhibitors: overview and perspectives. Molecular Cancer Research, 5(10), 981-989.

[78] Marks, P. A., \& Breslow, R. (2007). Dimethyl sulfoxide to vorinostat: development of this histone deacetylase inhibitor as an anticancer drug. Nature Biotechnology, 25(1), 84-90.

[79] Glaser, K.B. (2007). HDAC inhibitors: clinical update and mechanism-based potential. Biochemical Pharmacology, 74(5), 659-671.

[80] Sato, F., Tsuchiya, S., Meltzer, S. J., \& Shimizu, K. (2011). MicroRNAs and epigenetics. FEBS Journal , 278(10), 1598-1609. 
[81] Starczynowski, D. T., Morin, R., Mc Pherson, A., Lam, J., Chan, R., Wegrzyn, J., Kuchenbauer, F., Hirst, M., Tohyama, M., Humphries, R. K., Lam, W. L., Marra, M., \& Karsan, A. (2011). Genome-wide identification of human microRNAs located in leukemia-associated genomic alterations. Blood, 117(2), 595-607.

[82] Garzon, R., Heaphy, C. E., Havelange, V., Fabbri, M., Volinia, S., Tsao, T., Zanesi, N., Kornblau, S. M., Marcucci, G., Calin, G. A., Andreef, M., \& Croce, C. M. (2009). MicroRNA 29b functions in acute myeloid leukemia. Blood, 114(26), 5331-5341.

[83] Marcucci, G., Mrózek, K., Radmacher, M. D., Garzon, R., \& Bloomfield, C. D. (2011). The prognostic and functional role of microRNAs in acute myeloid leukemia. Blood, 117(4), 1121-1129.

[84] Duursma, A. M., Kedde, M., Schrier, M., le Sage, C., \& Agami, R. (2008). miR-148 targets human DNMT3b protein coding region. RNA, 14(5), 872-877.

[85] Sander, S., Bullinger, L., Klapproth, K., Fiedler, K., Kestler, H. A., Barth, T. F., Moller, P., Stilgenbauer, S., Pollack, J. R., \& Wirth, T. (2008). MYC stimulates EZH2 expression by repression of its negative regulator miR-26a. Blood, 112(10), 4202-4212.

[86] Swierczek, S., Yoon, D., Hickman, K., \& Prchal, J. T. (2010). MicroRNA-101 is downregulated in PV and ET granulocytes and its decrease is associated with over-expression of histone methyltransferase in EZH2 in MPN patients. Blood (ASH Annual Meeting Abstracts) 116 (21) 1989.

[87] Varambally, S., Cao, Q., Mani, R. S., Shankar, S., Wang, X., Ateeq, B., Laxman, B., Cao, X., Jing, X., Ramnarayanan, K., Brenner, J. C., Yu, J., Kim, J. H., Han, B., Tan, P., Kumar-Sinha, C., Lonigro, R. J., Palanisamy, N., Maher, C. A., \& Chinnaiyan, A. M. (2008). Genomic loss of microRNA-101 leads to overexpression of histone methyltransferase EZH2 in cancer. Science, 322(5908), 1695-1699.

[88] Friedman, J. M., Liang, G., Liu, C. C., Wolff, E. M., Tsai, Y. C., Ye, W., Zhou, X., \& Jones, P. A. (2009). The putative tumor suppressor microRNA-101 modulates the cancer epigenome by repressing the polycomb group protein EZH2. Cancer Research, 69(6), 2623-2629.

[89] Gandellini, P., Folini, M., Longoni, N., Pennati, M., Binda, M., Colecchia, M., Salvioni, R., Supino, R., Moretti, R., Limonta, P., Valdagni, R., Daidone, M. G., \& Zaffaroni, N. (2009). miR-205 exerts tumor-suppressive functions in human prostate through down-regulation of protein kinase Cepsilon. Cancer Research, 69(6), 2287-2295.

[90] Juan, A. H., Kumar, R. M., Marx, J. G., Young, R. A., \& Sartorelli, V. (2009). Mir-214dependent regulation of the polycomb protein Ezh2 in skeletal muscle and embryonic stem cells. Molecular Cell, 36(1), 61-74.

[91] Dostalova, Merkerova. M., Krejcik, Z., Votavova, H., Belickova, M., Vasikova, A., \& Cermak, J. (2011). Distinctive microRNA expression profiles in CD34+ bone marrow cells from patients with myelodysplastic syndrome. European Journal of Human Genetics, 19(3), 313-319. 
[92] Jólkowska, J., \& Witt, M. (2000). The EVI-1 gene-its role in pathogenesis of human leukemias. Leuk Res, 24, 553-558.

[93] Buonamici, S., Chakraborty, S., Senyuk, V., \& Nucifora, G. (2003). The role of EVI1 in normal and leukemic cells. Blood Cells, Molecules E Diseases, 31(2), 206-212.

[94] Wieser, R. (2007). The oncogene and developmental regulator EVI1 expression, biochemical properties, and biological functions. Gene, 396(2), 346-357.

[95] Fuchs, O. (2009). Zinc finger protein EVI1 and its role in normal development and in oncogenesis. Chapter 18 in Focus on Zinc Finger Protein Research, ed. K Yoshida, 303-319.

[96] Senyuk, V., Premanand, K., Xu, P., Qian, Z., \& Nucifora, G. (2011). The oncoprotein EVI1 and the DNA methyltransferase Dnmt3 co-operate in binding and de novo methylation of target DNA. PLOS One 6 (6), e20793.

[97] Yoshimi, A., \& Kurokawa, M. (2011). Evi1 forms a bridge between the epigenetic machinery and signalling pathway. Oncotarget, 2(7), 575-586.

[98] Yoshimi, A., Goyama, S., Watanabe-Okochi, N., Yoshiki, Y., Nannya, Y., Nitta, E., Arai, S., Sato, S., Shimabe, M., Nakayama, M., Imai, Y., Kitamura, T., \& Kurokawa, M. (2011). Evi1 represses PTEN expression and activates PI3K/AKT/mTOR via interactions with polycomb proteins. Blood, 117(13), 3617-3628.

[99] van Waalwijk, Barjesteh, van Doorn-Khosrovani, S., Erpelinck, C., van Putten, W.L.J., \& Valk, P.J.M. (2003). High EVI1 expression predicts poor survival in acute myeloid leukemia: a study of 319 de novo AML patients. Blood, 101(3), 837-845.

[100] Breccia, M., Cannella, L., Santopietro, M., Loglisci, G., Federico, V., Salaroli, A., Nanni, M., Mancini, M., \& Alimena, G. (2011). Azacitidine in myelodysplastic syndromes with inversion of chromosome 3. Leukemia, 25(4), 736-737.

[101] Garcia-Manero, G., \& Fenaux, P. (2011). Hypomethylating agents and other novel strategies in myelodysplastic syndromes. Journal of Clinical Oncology, 29(5), 516-523.

[102] Curik, N., Burda, P., Vargova, K., Pospisil, V., Belickova, M., Vlckova, P., Savvulidi, F., Necas, E., Hajkova, H., Haskovec, C., Cermak, J., Krivjanska, M., Trneny, M., Laslo, P., Jonasova, A., \& Stopka, T. (2012). 5azacitidine in aggressive myelodysplastic syndromes regulates chromatin structure at PU.1 gene and cell differentiation capacity. Leukemia DOI:leu.2012.47.

[103] Kagey, J. D., Kapoor-Vazirani, P., Mc Cabe, M. T., Powell, D. R., \& Vertino, P. M. (2010). Long-term stability of demethylation after exposure to 5-aza-2'-deoxycytidine correlates with sustained RNA polymerase II occupancy. Molecular Cancer Research, 8(7), 1048-1059.

[104] Sorm, F., Pískala, A., Cihák, A., \& Veselý, J. (1964). azacytidine, a new, highly effective cancerostatic. Experientia, 20(4), 202-203. 
[105] Veselý, J., Cihák, A., \& Sorm, F. (1968). Characteristics of mouse leukemic cells resistant to 5-azacytidine and 5-aza-2'-deoxycytidine. Cancer Research, 28(10), 1995-2000.

[106] Hollenbach, P. W., Nguyen, A. N., Brady, H., Williams, M., Ning, Y., Richard, N., Krushel, L., Aukerman, S. L., Heise, C., \& Mac Beth, K. J. (2010). A comparison of azacytidine and decitabine activities in acute myeloid leukemia cell lines. PLOS One, 5 (2) e9001.

[107] Silverman, L. R., Demakos, E. P., Peterson, B. L., Kornblith, A. B., Holland, J. C., Odchimar-Reissig, R., Stone, R. M., Nelson, D., Powell, B. L., De Castro, C. M., Ellerton, J., Larson, L. A., Schiffer, C. A., \& Holland, J. F. (2002). Randomized controlled trial of azacitidine in patients with the myelodysplastic syndrome: a study of the cancer and leukemia group B. Journal of Clinical Oncology, 20(10), 2429-2440.

[108] Fenaux, P., Mufti, G. J., Hellström-Lindberg, E., Santini, V., Finelli, C., Giagounidis, A., Schoch, R., Gattermann, N., Sanz, G., List, A., Gore, S. D., Seymour, J. F., Bennett, J. M., Byrd, J., Backstrom, J., Zimmerman, L., Mc Kenzie, D., Beach, C., \& Silverman, L. R. (2009). Efficacy of azacitidine compared with that of conventional care regimens in the treatment of higher-risk myelodysplastic syndromes, a randomised, open-label, phase III study. Lancet Oncology, 10(3), 223-232.

[109] Silverman, L. R., Fenaux, P., Mufti, G. J., Santini, V., Hellström-Lindberg, E., Gattermann, N., Sanz, G., List, A., Gore, S. D., \& Seymour, J. F. (2011). Continued azacitidine therapy beyond time of first response improves quality of response in patients with higher-risk myelodysplastic syndromes. Cancer, 117(12), 2697-2702.

[110] Itzykson, R., Thépot, S., Beyne-Rauzy, O., Ame, S., Isnard, F., Dreyfus, F., Salanoubat, C., Taksin, A. L., Chelgoum, Y., Berthon, C., Malfuson, J. V., Legros, L., Vey, N., Turlure, P., Gardin, C., Bohrer, S., Ades, L., \& Fenaux, P. (2012). Does addition of erythropoiesis stimulating agents improve the outcome of higher-risk myelodysplastic syndromes treated with azacytidine. Leukemia Research 36 (4), 397-400.

[111] Van der Helm, L. H., Alhan, C., Wijermans, P. W., van Marwijk, Kooy. M., Schaafsma, R., Biemond, B. J., Beeker, A., Hoogendoorn, M., van Rees, B. P., de Weerd, O., Wegman, J., Libourel, W. J., Luykx-de, Bakker. S., Minnema, M. C., Brouwer, R. E., Croon-de, Boer. F., Eefting, M., Jie, K. S., van de Loosdrecht, A. A., Koedam, J., Veeger, N.J., Veeger, E., \& Huls, G. (2011). Platelet doubling after the first azacitidine cycle is a promising predictor for response in myelodysplastic syndromes (MDS), chronic myelomonocytic leukaemias (CMML) and acute myeloid leukaemia (AML) patients in the Dutch azacitidine compassionate named patient programme. British Journal of Haematology, 155(5), 596-606.

[112] Pollyea, D. A., Raval, A., Kusler, B., Gotlib, J. R., Alizadeh, A. A., \& Mitchell, B. S. (2011). Impact of TET2 mutations on mRNA expression and clinical outcomes in MDS patients treated with DNA methyltransferase inhibitors. Hematological Oncology, 29(3), 157-160. 
[113] Hájková, H., Marková, J., Haškovec, C., Šárová, I., Fuchs, O., Kostečka, A., Cetkovský, P., Michalová, K., \& Schwarz, J. (2012). Decreased methylation in acute myeloid leukemia patients with DNMT3A mutations and prognostic implications of DNA methylation. Leukemia Research 2012 doi:j.leukres.05.012.

[114] Sekeres, M. A., List, A. F., Cuthbertson, D., Paquette, R., Ganetzky, R., Latham, D., Paulic, K., Afable, M., Saba, H. I., Loughran, T. P., \& Maciejewski, J. P. (2010). Phase I combination trial of lenalidomide and azacitidine in patients with higher-risk myelodysplastic syndromes. Journal of Clinical Oncology, 28(13), 2253-2258.

[115] Van den, Berghe. H., Cassiman, J. J., David, G., Fryns, J. P., Michaux, J. L., \& Sokal, G. (1974). Distinct haematological disorder with deletion of long arm of no. 5 chromosome. Nature, 251(5474), 437-438.

[116] Van den Berghe, H., \& Michaux, L. (1997). 5q-, twenty-five years later: a synopsis. Cancer Genetics and Cytogenetics, 94(1), 1-7.

[117] Boultwood, J., Pellagatti, A., Mc Kenzie, A. N., \& Wainscoat, J. S. (2010). Advances in the 5q- syndrome. Blood, 116(26), 5803-5811.

[118] Corral, L. G., Haslett, P. A., Muller, G. V., Chen, R., Wong, L. M., Ocampo, C. J., Patterson, R. T., Stirling, D. I., \& Kaplan, G. (1999). Differential cytokine modulation and $\mathrm{T}$ cell activation by two distinct classes of thalidomide analogues that are potent inhibitors of TNF-alpha. Journal of Immunology, 163(1), 380-386.

[119] Vallet, S., Palumbo, A., Raje, N., Boccadoro, M., \& Anderson, K. C. (2008). Thalidomide and lenalidomide: mechanism-based potential drug combinations. Leukemia $\mathcal{E}$ Lymphoma, 49(7), 1238-1245.

[120] Kotla, V., Goel, S., Nischal, S., Heuck, C., Vivek, K., Das, B., \& Verma, A. (2009). Mechanism of action of lenalidomide in haematological malignancies. Journal of Hematology and Oncology 2, 36.

[121] List, A., Kurtin, S., Roe, D. J., Buresh, A., Mahadevan, D., Fuchs, D., Rimsza, L., Heaton, R., Knight, R., \& Zeldis, J. B. (2005). Efficacy of lenalidomide in myelodysplastic syndromes. The New England Journal of Medicine, 352(6), 549-557.

[122] List, A., Dewald, G., Bennett, J., Giagounidis, A., Raza, A., Feldman, E., Powell, B., Greenberg, P., Thomas, D., Stone, R., Reeder, C., Wride, K., Patin, J., Schmidt, M., Zeldis, J., \& Knight, R. (2006). Myelodysplastic Syndrome-003 Study Investigators. Lenalidomide in the myelodysplastic syndrome with chromosome $5 \mathrm{q}$ deletion. The New England Journal of Medicine, 355(14), 1456-1465.

[123] Giagounidis, A., Fenaux, P., Mufti, G. J., Muus, P., Platzbecker, U., Sanz, G., Cripe, L., Von-Toal, Lilienfeld., , M., \& Wells, R. A. (2008). Practical recommendations on the use of lenalidomide in the management of myelodysplastic syndromes. Annals of Hematollogy, 87(5), 345-352.

[124] Giagounidis, A. A., Kulasekararaj, A., Germing, U., Radkowski, R., Haase, S., Petersen, P., Göhring, G., Büsche, G., Aul, C., Mufti, G. J., \& Platzbecker, U. (2012). Long- 
term transfusion independence in $\operatorname{del}(5 \mathrm{q})$ MDS patients who discontinue lenalidomide. Leukemia, 26(4), 855-858.

[125] Göhring, G., Lange, K., Hofmann, W., Nielsen, K. V., Hellström-Lindberg, E., Roy, L., Morgan, M., Kreipe, H., Büsche, G., Giagounidis, A., \& Schlegelberger, B. (2012). Telomere shortening, clonal evolution and disease progression in myelodysplastic syndrome patients with 5q deletion treated with lenalidomide. Leukemia, 26(2), 356-358.

[126] Jädersten, M., Saft, L., \& Pellagatti, A. (2009). Clonal heterogeneity in the 5q- syndrome: 53expressing progenitors prevail during lenalidomide treatment and expand at disease progression. Haematologica 94 (12) 1762-1766.

[127] Jädersten, M., Saft, L., Smith, A., Kulasekararaj, A., Pomplun, S., Göhring, G., Hedlund, A., Hast, R., Schlegelberger, B., Porwit, A., Hellström-Lindberg, E., \& Mufti, G. J. (2011). TP53 mutations in low-risk myelodysplastic syndromes with del(5q) predict disease progression. Journal of Clinical Oncology, 29(15), 1971-1979.

[128] Tehranchi, R., Woll, P. S., \& Anderson, K. (2010). Persistent malignant stem cells in del(5q) myelodysplasia in remission. The New England Journal of Medicine, 363(11), 1025-1037.

[129] Ebert, B. L., Prety, J., Bosco, J., Chang, C. Y., Tamazo, P., Galili, N., Raza, A., Root, D. E., Attar, E., Ellis, S. R., \& Golub, T. R. (2008). Identification of RPS14 as a 5q- syndrome gene by RNA interference screen. Nature, 451(7176), 335-339.

[130] Ebert B.L. (2009). Deletion 5q in myelodysplastic syndrome: a paradigm for the study of hemizygous deletions in cancer. Leukemia, 23(7), 1252-1256.

[131] Narla, A., \& Ebert, B. L. (2010). Ribosomopathies: human disorders of ribosome dysfunction. Blood, 115-3196.

[132] Czibere, A. G., Bruns, I., Junge, B., Singh, R., Kobbe, G., Haas, R., \& Germing, U. (2009). Low RPS14 expression is common in myelodysplastic syndromes without 5qaberration and defines a subgroup of patients with prolonged survival. Haematologica, 94(10), 1453-1455.

[133] Ebert, B. L., Galili, N., Tamayo, P., Bosco, J., Mak, R., Pretz, J., Tanguturi, S., LaddAcosta, C., Stone, R., Golub, T. R., \& Raza, A. (2008). An erythroid differentiation signature predicts response to lenalidomide in myelodysplastic syndrome. PLoS Medicine 5 (2) e35.

[134] Fenaux, P., Giagounidis, A., Selleslag, D., Beyne-Rauzy, O., Mufti, G., Mittelman, M., Muus, P., Te, Boekhorst. P., Sanz, G., Del Canizo, C., Guerci-Bresler, A., Nilsson, L., Platzbecker, U., Lübbert, M., Quesnel, B., Cazzola, M., Ganser, A., Bowen, D., Schlegelberger, B., Aul, C., Knight, R., Francis, J., Fu, T., \& Hellström-Lindberg, E. (2011). MDS-004 Lenalidomide del 5q Study Group. A randomized phase 3 study of lenalidomide versus placebo in RBC transfusion-dependent patients with low-/intermediate-1-risk myelodysplastic syndromes with del5q. Blood, 118(14), 3765-3776. 
[135] Le Bras, F., Sebert, M., Kelaidi, C., Lamy, T., Dreyfus, F., Delaunay, J., Banos, A., Blanc, M., Vey, N., Schmidt, A., Visanica, S., Eclache, V., Turlure, P., Beyne-Rauzy, O., Guerci, A., Delauer, A., de Botton, S., Rea, D., Fenaux, P., \& Adés, L. (2011). Treatment by lenalidomide in lower risk myelodysplastic syndrome with $5 q$ deletion-the GFM experience. Leukemia Research, 35(11), 1444-1448.

[136] Park, S., Vassilieff, D., Bardet, V., Viguié, F., \& Dreyfus, F. (2010). Efficacy of the association of lenalidomide to erythropoiesis-stimulating agents in del (5q) MDS patients refractory to single-agent lenalidomide. Leukemia, 24(11), 1960-1977.

[137] Narla, A., Dutt, S., Mc Auley, J. R., Al-Shahrour, F., Hurst, S., Mc Conkey, M., Neuberg, D., \& Ebert, B. L. (2011). Dexamethasone and lenalidomide have distinct functional effects on erythropoiesis. Blood, 118(8), 2296-2304.

[138] Cmejlova, J., Dolezalova, L., Pospisilova, D., Petrtylova, K., Petrak, J., \& Cmejla, R. (2006). Translational efficiency in patients with Diamond-Blackfan anemia. Haematologica, 91(11), 1456-1464.

[139] Pospisilova, D., Cmejlova, J., Hak, J., Adam, T., \& Cmejla, R. (2007). Successful treatment of a Diamond-Blackfan anemia patient with amino acid leucine. Haematologica 92 (5) e, 66-67.

[140] Payne, E., Virgilio, M., Narla, A., Sun, H., Levine, M., Paw, B. H., Berliner, N., Look, A. T., Ebert, B., \& Khanna-Gupta, A. (2011). L-leucine improves the anemia and developmental defects associated with Diamond-Blackfan anemia and del(5q) MDS by activating the mTOR pathway. Blood 2012 10.1182/ blood-10-382986

[141] Yip, B. H., Pellagatti, A., Vuppusetty, C., Giagounidis, A., Germing, U., Lamikanra, A. A., Roberts, D. J., Fernandez-Mercado, M., Mc Donald, E. J., Killick, S., Wainscoat, J. S., \& Boultwood, J. (2012). Effects of L-leucine in RPS14deficient erythroid cells. Leukemia leu.2012.82.

[142] Voutsadakis, I. A., \& Cairoli, A. (2012). A critical review of the molecular pathophysiology of lenalidomide sensitivity in 5q- myelodysplastic syndromes. Leukemia $\mathcal{E}$ Lymphoma, 53(5), 779-788.

[143] Wei, S., Chen, X., Rocha, K., Epling-Burnette, P. K., Djeu, J. Y., Liu, Q., Byrd, J., Sokol, L., Lawrence, N., Pireddu, R., Dewald, G., Williams, A., Maciejewski, J., \& List, A. (2009). A critical role for phosphatase haplodeficiency in the selective suppression of deletion 5q MDS by lenalidomide. Proceedings of the National Academy of Sciences of the United States of America, 106(31), 12974-12979.

[144] Moutouh-de, Parseval. L. A., Verhelle, D., Glezer, E., Jensen-Pergakes, K., Ferguson, G. D., Corral, L. G., Morris, C. L., Muller, G., Brady, H., \& Chan, K. (2008). Pomalidomide and lenalidomide regulate erythropoiesis and fetal hemoglobin production in human CD34+ cells. Journal of Clinical Investigation, 118(1), 248-258.

[145] Starczynowski, D. T., \& Karsan, A. (2010). Innate immune signaling in the myelodysplastic syndromes. Hematology/Oncology Clinics of North America, 24(2), 343-359. 
[146] Siva, K., Jaako, P., Miharada, K., Miharada, K., Rörby, E., Ehinger, M., Karlsson, G., \& Karlsson, S. (2012). SPARC is dispensable for murine hematopoiesis, despite its suspected pathophysiological role in 5q- myelodysplastic syndrome. Leukemia leu. 2012.97.

[147] Steensma, D. P., \& Stone, R. M. (2011). Lenalidomide in AML: del(5q) or who? Blood, 118(3), 481-482.

[148] Sugimoto, Y., Sekeres, M. A., \& Makishima, H. (2012). Cytogenetic and molecular predictors of response in patients with myeloid malignancies without del(5q) treated with lenalidomide. Journal of Hematology and Oncology 5, 4. 
